\title{
An Analysis of Poplar Growth and Quality Traits to Facilitate Identification of Climate-Adapted Plant Material for Sweden
}

\author{
Almir Karacic $^{1}$ (D) Anneli Adler ${ }^{1}$ (D) $\cdot$ Martin Weih $^{1}$ (D) Lars Christersson $^{1}$ (D)
}

Received: 8 July 2020 / Accepted: 16 October 2020 / Published online: 12 November 2020

(C) The Author(s) 2020

\begin{abstract}
Poplar plantations harbor large potential as a renewable source of biomass for bioenergy and other industrial applications. The overall aim of this study is to analyze growth, phenology, stem form, and branching characteristics of 32 poplar clones grown in a trial in southern Sweden for their suitability to be grown as industrial feedstock. In a linear mixed model, performed for diameter at breast height and stem volume, the precision was improved by the use of two competition indices. The significance of phenology and quality characteristics for growth performance and ranking of poplar clones was evaluated through genotypic correlations, and multivariate hierarchical cluster analysis used to group the material. All traits showed moderate to high broad sense heritability. In general, higher stem volume was positively correlated with later leaf senescence, and uncorrelated with spring phenology. Selection efficiency for stem diameter and height was greatly improved between age 3 and 6 years allowing a better precision in selecting a subset of clones to be further tested in production plots and pilot plantations. Two commercial Populus maximowiczii Henry $\times$ trichocarpa Torr. \& Gray cultivars performed best, while some intraspecific hybrids of $P$. trichocarpa are considered useful to genetically diversify commercial plantations in Southern Sweden (Belgian clones) or establish plantations in north-central parts of Sweden (Swedish clones). The cluster analysis emphasized growth traits and the grouping of the clones corresponded to their origin (or parentage). The results will facilitate decisions on the use of studied material in breeding, further testing and commercial deployment of poplar plantations in Sweden.
\end{abstract}

Keywords Genetic parameters $\cdot$ Growth performance $\cdot$ Multivariate analysis $\cdot$ Phenology $\cdot$ Populus trichocarpa $\cdot$ Stem quality

\section{Introduction}

Transformation towards sustainable land and material use benefits from an increased availability of fossil-free and regionally produced raw materials such as woody biomass. Fast-growing Populus species represent one potentially important biomass source $[1,2]$ with high biomass productivity $[3,4]$ and multiple industrial and environmental uses $[5,6]$. Currently, Swedish

Almir Karacic

almir.karacic@slu.se

Anneli Adler

anneli.adler@slu.se

Martin Weih

martin.weih@slu.se

Lars Christersson

lars.christersson@slu.se

1 Department of Crop Production Ecology, Swedish university of Agricultural Sciences, 75007 Uppsala, Sweden poplar feedstock is mixed in the pulping process (particularly for textile pulp) with other tree species, while tops and branches are used as fuel in combined heat and power plants (Anders Ekstrand, Södra - personal communication). Nevertheless, the anticipated use of poplar wood is much broader and includes sawn wood, plywood, and refined fuel products for vehicles and aviation. In any case, the economic and technological viability of poplars rests heavily on the access to reliable feedstock supply and its quality characteristics. This precondition greatly depends on availability of highly productive and climate-adapted poplar varieties. Currently, in Sweden, commercially deployable poplar varieties are reduced to clone "OP-42" (Populus maximowiczii Henry $\times P$. trichocarpa Torr. \& Gray) crossed in the 1920 s by Stout and Schreiner [7-9]. This clone has been planted since the 1990 s on some thousand hectares at latitudes $56^{\circ}-59^{\circ} \mathrm{N}$ reaching an annual biomass production of up to $10 \mathrm{Mg} \mathrm{ha}^{-1}$ year $^{-1}[4,10]$ within rotations of 18-25 years. However, operating with only one commercial variety represents an obstacle to further expansion of poplar plantations on the potentially available land area (0.5-2.5 million ha [11]), particularly in more harsh environments at higher latitudes. 
Breeding and selection of Populus in Sweden was first focused on hybrid aspen, whereas poplars have been only occasionally tested [12]. Development of bioenergy market in the 1970s and 1980s attracted renewed interest to poplars as an economically interesting alternative for farmers on the land set-aside from an overproducing agricultural sector. Poplar germplasm, originally introduced mainly from collections in the Netherlands and Germany, was later expanded with Belgian material consisting of $P$. trichocarpa and its hybrids with $P$. deltoides Bartr. Ex Marsh. and with IUFRO [13] material imported mainly from Finland [14]. After initial evaluations, Belgian clones were considered unsuitable for central Sweden, but partly usable in southern Sweden [15, 16]. In 1990s, a short poplar breeding program was started as a result of a growing insight into the importance of adaptation of material for Swedish climate conditions. The focus was entirely on $P$. trichocarpa using parentage from maritimecontinental and south-north transects at $45-60^{\circ} \mathrm{N}[17,18]$. A relatively small portion of the resulting progeny population was saved and is presently under field evaluation across the whole Baltic Region. Six clones from this program were included in the trial presented here.

So far, poplar breeding programs have been mainly focused on producing material suitable for temperate climate regions at latitudes between $30^{\circ} \mathrm{N}$ and $50^{\circ} \mathrm{N}$ [19-22]. Such material lacks necessary hardiness when planted at higher latitudes $\left(55^{\circ} \mathrm{N}-65^{\circ} \mathrm{N}\right)$, which has been confirmed in a number of north European field trials [15, 16, 18, 23-25]. This maladaptation has its cause in phenotypic mismatch, usually related to delayed autumnal transition from growth to dormancy [26, 27]. In $P$. trichocarpa, this transition is mainly governed by photoperiod signals for growth cessation triggered at longer days in northern compared to southern ecotypes [26, 28]. Thus, while highly productive varieties of southern origin tend to set buds too late or inadequately when grown at higher latitudes, there is also a clear trend of prolonged periods of shoot elongation to be correlated with higher biomass production $[15,16,18,23-25$, 29-33]. Such a trade-off between competitive advantages of a longer seasonal growth and survival due to timely termination of growth is under strong selection pressure in natural populations of Populus spp. [31, 34]. Consequently, even the adaptation of poplars outside their natural range will rest on our ability to develop criteria for adequate balance of biomass productivity and phenology timing under the specific photoperiod and temperature conditions in different parts of Sweden.

In many studies on poplar clones, multiple traits have been used to evaluate poplar material using multivariate analytic tools $[30,35-39]$. In the present study, we use some quality traits along with growth and phenology variables, adding thus the potential end use value as the evaluation criterion. The overall aim of this study was to analyze growth, phenology, stem form, and branching characteristics of 32 poplar clones grown in southern Sweden for their suitability as industrial feedstock. The specific aims were to (i) estimate the genotypic components of clonal variation for various traits, (ii) evaluate correlations between phenology and clonal growth performance, (iii) analyze age-dependent correlations of growth traits and their impact on selection efficiency, and (iv) group the material using multiple traits for growth performance, phenology, and quality characteristics. This study will improve our understanding of the importance of phenological and stem quality traits in the selection of poplar clones for Swedish climate conditions.

\section{Material and Methods}

\section{Climate and Soil}

The trial was located at the Swedish west coast, outside the city of Halmstad $\left(56^{\circ} 41^{\prime} \mathrm{N} ; 12^{\circ} 56^{\prime} \mathrm{E}\right)$, a region with temperate climate, naturally dominated by deciduous broadleaved forests. During the study period, between 2007 and 2018, all important climate parameters corresponded to the average values for the standard reference period 1961-90. The mean annual temperature was $8.2{ }^{\circ} \mathrm{C}$, equaling an average value of 1783 growing degree days, whereas the total annual precipitation was $864 \mathrm{~mm}$, with $371 \mathrm{~mm}$ falling during the period of intensive growth in May-August. The temperature-based average length of growing season (SMHI 2020 - Open data, Swedish Meteorological and Hydrological Institute) is 210 days beginning in early April and ending in the first week of November. The mean temperature during the growing season was $13.1{ }^{\circ} \mathrm{C}$ and the first autumn frosts occurred usually first between October 31 and November 15 or later.

The soil has developed on relatively deep postglacial sand (SGU - Geological Survey of Sweden) with sandy loam/loamy sand texture for $0-20$ and $20-50-\mathrm{cm}$ layers, respectively. Blocks I and II were located on the northern slope, whilst blocks III and IV were placed at the bottom of the slope where ground water table was occasionally high, decreasing the tree survival in a part of block III. The soil $\mathrm{pH}$ was 5.5; there was $2 \%$ of organic $\mathrm{C}$ within $20 \mathrm{~cm}$ topsoil, while the $\mathrm{NO}_{3}$ and $\mathrm{NH}_{4}$ nitrogen amounted to approximately $30 \mathrm{~kg} \mathrm{ha}^{-1}$.

\section{Trial Design and Plant Material}

After appropriate soil preparation and weed treatment the trial was established in June 2007 by planting 1-year-old, containerized seedlings of 32 poplar clones. A randomized 4-block design was applied with a $3 \times 3 \mathrm{~m}$ planting spacing, 5-trees line plots, totaling 20 trees per clone. The poplar clones originated from four major sources; (i) P. trichocarpa and P. trichocarpa $\times$ deltoides bred at Geraardsbergen, Belgium (BELt and BELtd), preliminary evaluated by Christersson [16], (ii) six clones of $P$. trichocarpa bred for central Sweden $\left(58^{\circ}-62^{\circ} \mathrm{N}\right.$, 
SLUc - for central Sweden and SLUn-for the southern part of Swedish northern provinces) [14], (iii) 17 progenies of P. trichocarpa from Prince George $\left(\mathrm{PG}, 54^{\circ} \mathrm{N}\right)$ including two additional progenies of $P$. balsamifera from Forth Nelson $\left(\mathrm{FN}, 58^{\circ} \mathrm{N}\right)$, British Columbia, Canada, and finally (iv) two reference clones $(\mathrm{REF})$ of $P$. maximowiczii $\times$ trichocarpa, "OP-42" and "OP-41" (Table 1). The Kinship coefficient between the two reference clones is 0.464 (Pär Ingvarsson, SLU, Uppsala, Sweden-personal communication). Considering that the expected value for monozygotic twins is 0.5 and 0.25 for full-sibs, it appears that the clone identified as "OP-41" most probably is "OP-42." However, we decided to treat them as two different clones in our statistical analysis.

\section{Measurements and Sampling}

Diameter at breast height $(D)$ and tree height $(H)$ were measured repeatedly in 3-year intervals. In 2015, we visually assessed stem form and branching, and measured the occurrence and height of top dominance loss, crooks and forks (Table S1). Phenology of bud burst (BB) was inventoried in 4-6-day intervals between end of March and the beginning of May 2010 by observing six different developmental stages: BB0, closed bud; $\mathrm{BB} 1$, initial shoot emergence; $\mathrm{BB} 2$ and $\mathrm{BB} 3$, the two phases defined by the length of primordial expansion outside the bud scales; BB4, leaves half shed (still rolled), bud scales wide open or shed; and BB5, leaves completely unrolled. Julian day (doy) for bud burst phase BB3 was selected as the starting point of canopy growth. To compensate for inventor's bias and due to periodic oscillation of temperature between screening occasions, we used all the observations of bud burst to slightly correct timing of BB3 for each clone (Supplementary Information, S2). Changes in autumn crown color and defoliation were registered between the end of September and mid-November 2018. The color change was screened separately for 1-year-old shoots (TC), and for older parts of crown (CRC) using the 0-2 scale, i.e., 0, green; 1, yellow-green; and 2, yellow. The same scale was used for leaf shed (LS), i.e., 0, less than 33\%; $1-33 \%$ to $66 \%$; and 2, more than $66 \%$ leaves shed (Table 2). Bud burst was inventoried in 2010 and leaf senescence in 2018. Consequently, clone canopy durations (CADU), calculated between BB3 and different autumn variables were hypothetical. Here, we made assumption that relative comparison of CADU among different clones will be meaningful, and also usable to compare the correlations of CADU with growth traits. In some cases, doy of phenological stages was not recorded, so that linear estimates were made for each single tree between two consecutive observations, for example, between BB2 and BB4 or for CRC2 when it was not registered.

\section{Calculations and Statistical Analysis}

In January 2019, 39 trees of 13 clones were thinned out from the trial and used to model volume growth based on diameter measurements along the stem in 2-m segments. Obtained parameters were used to estimate stem volume of all clones in the trial at all ages according to following function:

$V=e^{(b 1+b 2 \times \ln \mathrm{D}+\mathrm{b} 3 \times \ln \mathrm{H})}$

where $V\left(\mathrm{dm}^{3}\right.$, i.e., $\left.\mathrm{m}^{3} / 1000\right)$ is stem volume on bark, $D(\mathrm{~cm}$, i.e. $\mathrm{mm} / 10)$ is the breast height diameter, $H(\mathrm{~m})$ is total tree

Table 1 The origin and parentage of the poplar material

\begin{tabular}{|c|c|c|c|c|}
\hline Clone & Species & Group & Female parent & Male parent \\
\hline OP-41 & $\mathrm{M} \times \mathrm{T}$ & REF & Japan & Washington \\
\hline OP-42 & $\mathrm{M} \times \mathrm{T}$ & REF & Japan & Washington \\
\hline 15.7 & $\mathrm{~T} \times \mathrm{T}$ & SLUc & 216 (1560) Lincoln Island, Alaska 58³0’N & 290, Unknown \\
\hline 21.9 & $\mathrm{~T} \times \mathrm{T}$ & SLUc & $230(69.094 / 6)$ Abbots Ford, BC & 236; V235 (Washington) $\times$ V23 (Idaho) \\
\hline 23.4 & $\mathrm{~T} \times \mathrm{T}$ & SLUc & $230(69.094 / 6)$ Abbots Ford, BC & Kenai Island, Alaska \\
\hline 26.1 & $\mathrm{~T} \times \mathrm{T}$ & SLUc & $230(69.094 / 6)$ Abbots Ford, BC & 299 (910), Washington \\
\hline $70.038 / 20$ & $\mathrm{~T} \times \mathrm{T}$ & BELt & S.3-31 (Michigan) & V24 (Oregon, Columbia River) \\
\hline $70.038 / 67$ & $\mathrm{~T} \times \mathrm{T}$ & BELt & S.3-31 (Michigan) & V24 (Oregon, Columbia River) \\
\hline $70,039 / 24$ & $\mathrm{~T} \times \mathrm{T}$ & BELt & S.192-5 (Idaho) & V24 (Oregon, Columbia River) \\
\hline 44.7 & $\mathrm{~T} \times \mathrm{T}$ & SLUn & 70.039/? (S.192-5 (Idaho) × V24/36 (Oregon $)$ & 299 (910) Washington \\
\hline 44.11 & $\mathrm{~T} \times \mathrm{T}$ & SLUn & 70.039/? (S.192-5 (Idaho) × V24/36 (Oregon) & 299 (910) Washington \\
\hline $69.037 / 2$ & $\mathrm{~T} \times \mathrm{D}$ & BELtd & V235 (Washington) & S.620-543 (Michigan) \\
\hline $70,045 / 1$ & $\mathrm{~T} \times \mathrm{D}$ & BELtd & V235 (Washington) & S.520-225 (Michigan) \\
\hline PG clones & $\mathrm{T}$ & PG & PG1, PG2, .., PG5 (Prince George, BC) & Unknown \\
\hline FN clones & $\mathrm{B}$ & $\mathrm{FN}$ & FN3 and FN5 (Forth Nelson, BC) & Unknown \\
\hline
\end{tabular}

M, P. maximowiczii; T, P. trichocarpa; $D, P$. deltoides; and $B, P$. balsamifera 
Table 2 List of variables and acronyms used to characterize growth, phenology, and quality of trees grown in a 12-year-old poplar trial in southern Sweden

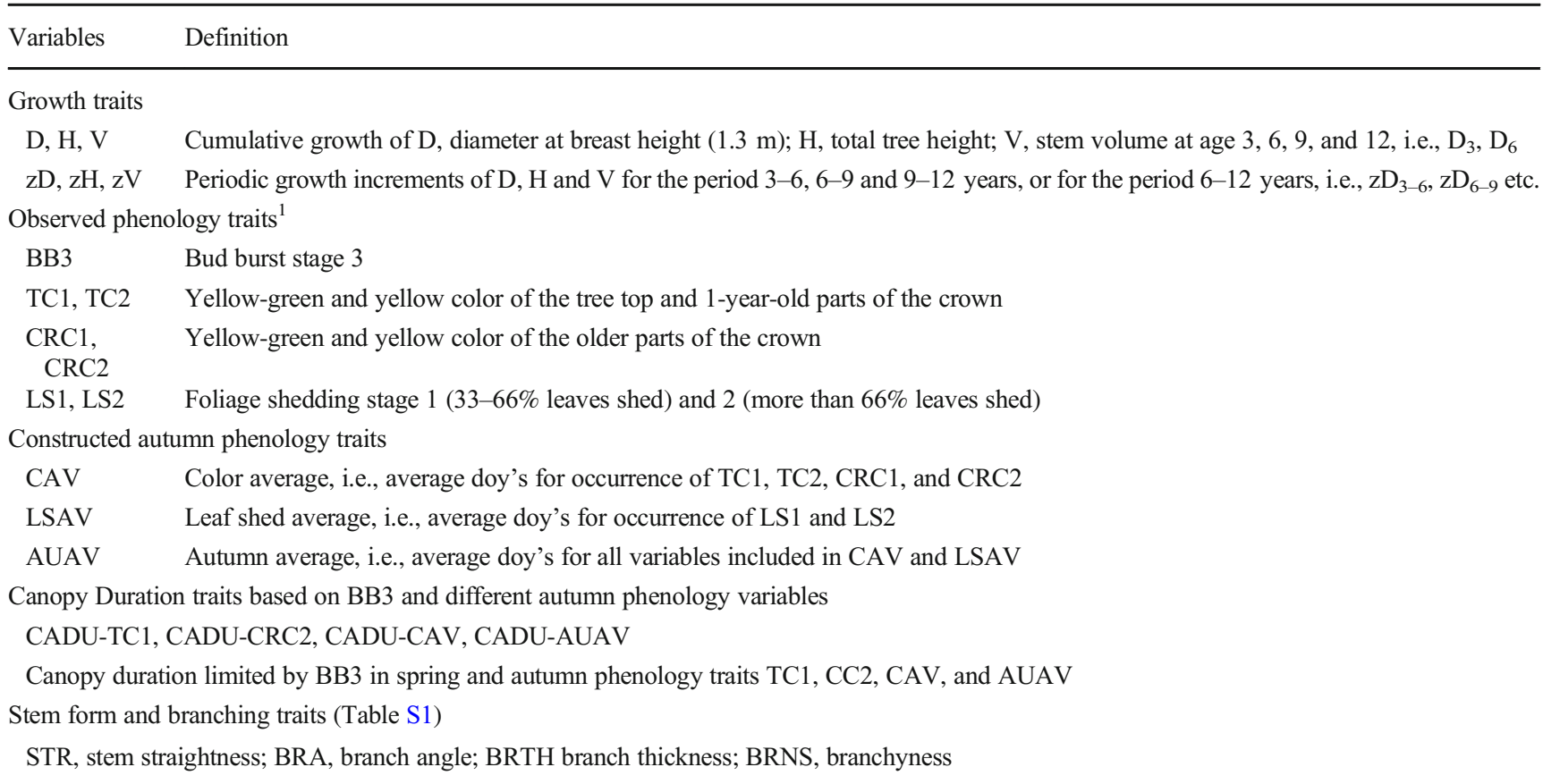

${ }^{1}$ Phenology variables are expressed as day of year (doy) for the first occurrence of a certain phenology stage or as an average doy for the first occurrence of phenology traits included in the constructed variables

height, and $\mathrm{b} 1=-3.53769, \mathrm{~b} 2=1.70873$, and $\mathrm{b} 3=1.35448$ are the estimated equation parameters.

Variance analysis of phenology variables was performed using mixed model procedure with the restricted maximum likelihood method to estimate the effects of fixed and random components. $Z$ and $F$ tests were used to determine significance of random and fixed effects respectively. The following linear model was used for analyses of all phenology variables:

$Y_{\mathrm{jkl}}=\mu+C_{j}+B_{k}+e_{\mathrm{jkl}}$

where $Y_{\mathrm{jk} 1}$ represents an observation on the $l^{\text {th }}$ line plot (average value of the five individuals in a line plot) on a $j^{\text {th }}$ clone within $k^{\text {th }}$ block, $\mu$ is the overall mean, and $e_{\mathrm{jkl}}$ is random error. The random clonal component was assumed to have normal distribution with the expectation of zero and corresponding $\sigma_{c}^{2}$ and $\sigma_{e}^{2}$. The analyzed variables are presented in Table 2 .

In the analyses of $\mathrm{D}, \mathrm{H}$, and $\mathrm{V}$, and the corresponding periodic increments $(\mathrm{zD}, \mathrm{zH}, \mathrm{zV})$ additional random spatial components were introduced in the mixed model representing row-column within-block matrices. Two competition indices were also calculated and used as covariates, i.e., sum of line lengths (SLL) [40] and neighbor plots (NP). The competition indices compensated for differences in growing space caused by early mortality and the edge effects. SLL was calculated for every single tree, then averaged for each line plot entry:

$\mathrm{SLL}_{i}=\sum_{j=1}^{8} \frac{D_{i}}{D_{i}+D_{j}} \times R$ Dist

where $\mathrm{SLL}_{i}$ is the competition index value of a target tree, $D_{i}$ is the breast height diameter of a target tree, $D_{j}$ is the breast height diameter of a neighbor tree, and $R$ Dist is the relative distance to the neighbor trees in a quadratic design, equaling 1 for perpendicular and 1.41 for diagonal neighbors. The NP index was emphasizing the competition effects of the two nearest neighboring line plots using the mean values per plot and was calculated as

$\mathrm{NP}_{\mathrm{tp}}=\frac{D_{\mathrm{tp}}}{D_{\mathrm{np} 1}+D_{\mathrm{np} 2}}$

where $\mathrm{NP}_{\mathrm{tp}}$ is the index value for the target plot, $D_{\mathrm{tp}}$ is the mean breast height diameter of the target plot, and $D_{\text {np1 }}$ and $D_{\mathrm{np} 2}$ are the mean breast height diameters of the nearest line plots on both sides of the target line plot.

Analysis of variance for growth variables at different ages was performed using a mixed model procedure with the following basic linear model:

$Y_{\mathrm{ijk} \mathrm{l}}=\mu+C_{i}+B_{j}+r_{k(j)}+c_{l(j)}+\mathrm{SLL}+\mathrm{NP}+e_{\mathrm{ijk} 1}$ 
where $Y_{\mathrm{ijk1}}$ represents the estimated value of clone $i$, block $j$ in row $k(j)$, and column $l(j)$, and $e_{\mathrm{ijkl}}$ is random error, while $C_{i}$, $r_{k(j)}$, and $c_{l(j)}$ were entered as random variables in the model. The competition indices, SLL and NP, were entered as covariances always representing the relationships among neighbor trees and plots from the end of the previous 3-year period, i.e., in the model for $\mathrm{D}_{6}$ ( $\mathrm{D}$ at age 6 ) we used competition indices calculated for trees and plots at the age of 3 years. The model runs for the first 3-year period did not include competition indices as they were negligible at this stage with the $3 \times 3 \mathrm{~m}$ spacing applied here. The competition indices were omitted from the analysis for $H$ and $\mathrm{zH}$, as the effect of competition on height increment could not be clearly anticipated. Block effects were omitted in the analysis of variance for stem form and branching as well as competition indices except for applying SLL for branchiness and branch thickness.

Variance components of random effects were derived from the mixed models runs for each trait. Genetic relatedness (Table 1) was not taken into account and clones were treated as independent genotypes. The genotypic clonal variance component, here corresponding to broad sense heritability, was calculated as

$\sigma_{G}^{2}=\sigma_{c}^{2} /\left(\sigma_{c}^{2}+\sigma_{e}^{2}\right)$

where $\sigma_{c}^{2}$ is the clonal variance component and $\sigma_{e}^{2}$ is the residual variance. The genotypic coefficient of variation was calculated as follows:

$C V_{G}=\sqrt{\sigma_{c}^{2}} \times 100 / \widehat{\mu}$

where $\widehat{\mu}$ is the predicted grand mean in the mixed model. The repeatability of clonal means was estimated as follows:

$R_{c}^{2}=\sigma_{c}^{2} /\left(\sigma_{c}^{2}+\sigma_{e}^{2} / k\right)$

where $k$ represents the harmonic mean number of replications per clone, i.e., harmonic mean number of line plots. The standard errors of repeatability estimates were calculated according to following formula [41]:

$\operatorname{se} R_{c}^{2}=\sqrt{\frac{2(n-1)\left(1-R_{c}^{2}\right)^{2}\left\lfloor 1+(k-1) R_{c}^{2}\right\rfloor^{2}}{k^{2}(n-N)(N-1)}}$

where $N$ is the number of clones and $n$ the total number of entries. The Pearson correlation coefficient was calculated for a large number of traits, while the relative selection efficiency of a trait $Y\left(\mathrm{RS}_{y}\right)$ as related to the direct selection of the target trait $X\left(S_{x}\right)$, in this case $V_{12}$ :

$\mathrm{RS}_{y} / S_{x}=H_{y} r_{G} /\left(H_{x}\right)$, where $H_{y}$ and $H_{x}$ equal square root of broad sense heritability for the indirect trait $Y\left(\sigma_{\mathrm{GY}}\right)$ and the directly selected trait $X$ $\left(\sigma_{\mathrm{GX}}\right)$, whereas $r_{G}$ is the genotypic correlation between traits $X$ and $Y$ [42].

Hierarchical cluster analysis was used to visualize the structuring of the tested material according to selected traits. The analysis included four variables for growth performance $\left(\mathrm{D}_{12}, \mathrm{H}_{12}, \mathrm{zD}_{6-12}, \mathrm{zH}_{6-12}\right)$, two for phenology (BB3 and CRC2), one for stem form (STR) and one for branchiness (BRNS). Prior to analysis all eight variables were standardized at the range -1 to 1 . Euclidian distance was used as a measure of similarity that was fixed at 70 and complete linkage was applied as a clustering algorithm. The cluster analysis and all other statistical runs were performed in Minitab 18.

\section{Results}

\section{Superior Performance of Reference Clones}

The two reference clones (REF) established their dominance during the period between age 3 and 6 years reaching at age 12 a mean diameter of $260 \mathrm{~mm}$ and a height above $20 \mathrm{~m}$ (Fig. 1). Belgian (BELt) and Swedish (SLUc) clones achieved on average $70 \%$ of REF stem volume by the age of 12 years. Across the 12-year period, BELt material was steadily closing the gap to REF, while SLUc decreased their relative performance from the initial $94 \%$ of REF at age 3 (Fig. 1d). The superior performance of REF clones is reflected by a sustained better diameter growth (Fig. 1a), along with good height growth performance except during the last 3-year period (age 912 years, Fig. 1c). The Belgian $\mathrm{T} \times \mathrm{D}$ (Table 1) clones (BELtd), Swedish SLUn, and four best PG clones (PG4best) reached only $40 \%$ of REF stem volume at age 12 years. Apart from REF, the best performing new clone was "21.9" (SLUc) with $18 \%$ lower mean stem volume compared to "OP-42." The broad sense heritabilities $\left(\sigma_{G}^{2}\right)$ for the growth variables were high (cumulative $D, H$, and $V$ ) or moderate to high (periodic growth increments $\mathrm{zD}, \mathrm{zH}$, and $\mathrm{zV}$ ), ranging from 0.43 for $\mathrm{zD}_{9-12}$ to 0.87 for $H_{12}$. The $\left(\sigma_{G}^{2}\right)$ values increased slightly with age for cumulative growth and decreased for periodic increments. The exception from this trend was $\sigma_{G}^{2}$ for $\mathrm{zV}$ that stayed unchanged during the period 3-12 years (Table 3).

\section{Strong Age-Age Correlations Enabled Early Selection of Clones}

The correlations between values of traits at different ages, known as age $\times$ age correlations $\left(r_{G}\right)$, were 0.81 and 0.90 for $\mathrm{D}_{3} \times \mathrm{D}_{12}$, and $\mathrm{H}_{3} \times \mathrm{H}_{12}$ respectively. Initial growth variables, i.e., $\mathrm{D}_{3}$ and $\mathrm{H}_{3}$, were moderately to strongly correlated with 
Table 3 Results of the linear mixed model analysis of growth, phenology, stem form, and branching properties of poplar clones grown in southern Sweden. Variance components for random effects were divided between the clone effects $\left(\sigma_{G}{ }^{2}\right.$, corresponding to broad sense heritability) and error $\left(\sigma_{e}{ }^{2}\right)$, which includes both random error and within-block variance component that was relatively small in most cases. $R_{c}{ }^{2}$ is repeatability of clonal means, $\mathrm{CV}_{G}$ and $\mathrm{CV}_{e}$ are coefficients of variation of $\sigma_{G}^{2}$ and $\sigma_{e}{ }^{2}$; SLL and NP are the competition indices; $F$ and $p$ values are provided for the effects of block and two competition indices used as covariance in some models. The variables were described in Table 2

\begin{tabular}{|c|c|c|c|c|c|c|c|c|c|c|c|c|}
\hline \multirow[t]{2}{*}{ Trait } & \multirow[t]{2}{*}{$\sigma_{G}^{2}$} & \multirow[t]{2}{*}{$\sigma_{e}^{2}$} & \multirow[t]{2}{*}{$R_{c}^{2} \pm \mathrm{SE}$} & \multirow{2}{*}{$\begin{array}{l}\mathrm{CV}_{G} \\
(\%)\end{array}$} & \multirow{2}{*}{$\begin{array}{l}\mathrm{CV}_{e} \\
(\%)\end{array}$} & \multicolumn{2}{|l|}{ SLL } & \multicolumn{2}{|l|}{ NP } & \multicolumn{2}{|l|}{ Block } & \multirow{2}{*}{$\begin{array}{l}R_{\mathrm{adj}}^{2} \\
(\%)\end{array}$} \\
\hline & & & & & & $F$ & $p$ & $F$ & $p$ & $F$ & $p$ & \\
\hline $\mathrm{D}_{3}$ & 0.75 & 0.25 & $0.92 \pm 0.02$ & 17.9 & 10.5 & $*$ & $*$ & $*$ & $*$ & 1.65 & 0.226 & 93.94 \\
\hline $\mathrm{D}_{6}$ & 0.79 & 0.21 & $0.93 \pm 0.02$ & 28.6 & 14.8 & 0.7 & 0.405 & 8.04 & 0.006 & 9.9 & 0.002 & 99.44 \\
\hline $\mathrm{D}_{9}$ & 0.83 & 0.17 & $0.95 \pm 0.01$ & 24 & 11 & 5.31 & 0.024 & 8.33 & 0.005 & 6.49 & 0.01 & 95.69 \\
\hline $\mathrm{D}_{12}$ & 0.82 & 0.18 & $0.95 \pm 0.02$ & 24.7 & 11.6 & 17.8 & 0 & 7.11 & 0.009 & 4.44 & 0.033 & 95.89 \\
\hline $\mathrm{H}_{3}$ & 0.79 & 0.21 & $0.93 \pm 0.02$ & 12.1 & 6.4 & $*$ & $*$ & $*$ & $*$ & 2.01 & 0.162 & 97.34 \\
\hline $\mathrm{H}_{6}$ & 0.79 & 0.21 & $0.93 \pm 0.02$ & 22.3 & 11.6 & $*$ & $*$ & $*$ & $*$ & 7.26 & 0.005 & 99.48 \\
\hline $\mathrm{H}_{9}$ & 0.83 & 0.17 & $0.95 \pm 0.01$ & 20.9 & 9.4 & $*$ & $*$ & $*$ & $*$ & 9.33 & 0.004 & 98.12 \\
\hline $\mathrm{H}_{12}$ & 0.87 & 0.13 & $0.96 \pm 0.01$ & 21.8 & 8.5 & $*$ & $*$ & $*$ & $*$ & 9.46 & 0.002 & 99.99 \\
\hline $\mathrm{V}_{3}$ & 0.74 & 0.26 & $0.92 \pm 0.02$ & $*$ & $*$ & $*$ & $*$ & $*$ & $*$ & 1.79 & 0.199 & 95.79 \\
\hline $\mathrm{V}_{6}$ & 0.82 & 0.18 & $0.95 \pm 0.02$ & 17.3 & 8.1 & 4.35 & 0.042 & 12.94 & 0.001 & 11.76 & 0.001 & 99.24 \\
\hline $\mathrm{V}_{9}$ & 0.83 & 0.17 & $0.95 \pm 0.01$ & 32.7 & 14.6 & 0.68 & 0.412 & 6.59 & 0.012 & 8.14 & 0.004 & 97.80 \\
\hline $\mathrm{V}_{12}$ & 0.84 & 0.16 & $0.95 \pm 0.01$ & 31.6 & 13.6 & 12.73 & 0.001 & 6.36 & 0.014 & 6.23 & 0.013 & 98.67 \\
\hline $\mathrm{zD}_{3-6}$ & 0.76 & 0.24 & $0.92 \pm 0.02$ & 27.5 & 15.7 & 0.55 & 0.459 & 6.85 & 0.01 & 13.49 & 0.001 & 92.50 \\
\hline $\mathrm{zD}_{6-9}$ & 0.63 & 0.37 & $0.87 \pm 0.03$ & 18.9 & 14.5 & 38.04 & 0 & 1.62 & 0.207 & 7.25 & 0.003 & 95.92 \\
\hline $\mathrm{zD}_{9-12}$ & 0.43 & 0.57 & $0.74 \pm 0.06$ & 20.5 & 23.7 & 88.23 & 0 & 0.02 & 0.881 & 0.54 & 0.658 & 99.35 \\
\hline $\mathrm{zH}_{3-6}$ & 0.69 & 0.31 & $0.90 \pm 0.03$ & 21.5 & 14.4 & $*$ & $*$ & $*$ & $*$ & 9.15 & 0.002 & 99.54 \\
\hline $\mathrm{zH}_{6-9}$ & 0.65 & 0.35 & $0.88 \pm 0.03$ & 22.3 & 16.5 & $*$ & $*$ & $*$ & $*$ & 8.98 & 0.005 & 91.64 \\
\hline $\mathrm{zH}_{9-12}$ & 0.53 & 0.47 & $0.81 \pm 0.05$ & 25.3 & 23.8 & $*$ & $*$ & $*$ & $*$ & 4.13 & 0.038 & 93.16 \\
\hline $\mathrm{zV}_{3-6}$ & 0.81 & 0.19 & $0.97 \pm 0.01$ & 34.2 & 16.6 & 4.66 & 0.037 & 12.86 & 0.001 & 13.85 & 0.001 & 98.66 \\
\hline $\mathrm{zV}_{6-9}$ & 0.82 & 0.18 & $0.97 \pm 0.01$ & 31.5 & 14.7 & 2.78 & 0.1 & 4.82 & 0.031 & 8.03 & 0.005 & 96.91 \\
\hline $\mathrm{zV}_{9-12}$ & 0.80 & 0.20 & $0.93 \pm 0.02$ & 30.6 & 15.3 & 31.76 & 0 & 4.03 & 0.048 & 4.21 & 0.04 & 99.08 \\
\hline BB3 & 0.90 & 0.10 & $0.97 \pm 0.01$ & 2.9 & 0.9 & $*$ & $*$ & $*$ & $*$ & 4.43 & 0.006 & 92.63 \\
\hline TC1 & 0.73 & 0.27 & $0.91 \pm 0.02$ & 3.3 & 2.0 & $*$ & $*$ & $*$ & $*$ & 1.52 & 0.214 & 79.50 \\
\hline $\mathrm{CRC} 1$ & 0.71 & 0.29 & $0.90 \pm 0.03$ & 2.9 & 1.9 & $*$ & $*$ & $*$ & $*$ & 3.69 & 0.015 & 78.29 \\
\hline $\mathrm{CRC} 2$ & 0.83 & 0.17 & $0.95 \pm 0.01$ & 3.8 & 1.7 & $*$ & $*$ & $*$ & $*$ & 0.4 & 0.75 & 87.31 \\
\hline LS1 & 0.72 & 0.28 & $0.91 \pm 0.03$ & 3.3 & 2.1 & $*$ & $*$ & $*$ & $*$ & 2.9 & 0.039 & 78.31 \\
\hline LS2 & 0.84 & 0.16 & $0.95 \pm 0.01$ & 4.0 & 1.7 & $*$ & $*$ & $*$ & $*$ & 5.42 & 0.002 & 88.02 \\
\hline CAV & 0.84 & 0.16 & $0.95 \pm 0.01$ & 3.3 & 1.4 & $*$ & $*$ & $*$ & $*$ & 0.45 & 0.721 & 88.09 \\
\hline LSAV & 0.83 & 0.17 & $0.95 \pm 0.01$ & 3.7 & 1.7 & $*$ & $*$ & $*$ & $*$ & 5.37 & 0.002 & 87.36 \\
\hline AUAV & 0.86 & 0.14 & $0.96 \pm 0.01$ & 3.4 & 1.4 & $*$ & $*$ & $*$ & $*$ & 2.03 & 0.115 & 89.55 \\
\hline CADU-CRC2 & 0.82 & 0.18 & $0.95 \pm 0.02$ & 5.7 & 2.7 & $*$ & $*$ & $*$ & $*$ & $*$ & $*$ & 88.60 \\
\hline CADU-TC1 & 0.71 & 0.29 & $0.90 \pm 0.03$ & 5.0 & 3.3 & $*$ & $*$ & $*$ & $*$ & $*$ & $*$ & 77.25 \\
\hline CADU-CAV & 0.82 & 0.18 & $0.95 \pm 0.01$ & 5.1 & 2.4 & $*$ & $*$ & $*$ & $*$ & $*$ & $*$ & 87.77 \\
\hline CADU-AUAV & 0.85 & 0.15 & $0.96 \pm 0.01$ & 5.3 & 2.3 & $*$ & $*$ & $*$ & $*$ & $*$ & $*$ & 90.45 \\
\hline STR & 0.58 & 0.42 & $0.84 \pm 0.04$ & 14.1 & 12.1 & $*$ & $*$ & $*$ & $*$ & $*$ & $*$ & 80.84 \\
\hline BRA & 0.62 & 0.38 & $0.86 \pm 0.04$ & 13.9 & 10.9 & $*$ & $*$ & $*$ & $*$ & $*$ & $*$ & 75.63 \\
\hline BRTH & 0.60 & 0.40 & $0.85 \pm 0.04$ & 20.4 & 16.6 & 30.70 & 0 & $*$ & $*$ & $*$ & $*$ & 85.94 \\
\hline BRNS & 0.80 & 0.20 & $0.94 \pm 0.02$ & 25.3 & 12.6 & 41.44 & 0 & $*$ & $*$ & $*$ & $*$ & 92.02 \\
\hline
\end{tabular}

subsequent periodic 3-year increments ranging from 0.57 to 0.90 (Table S2A). The merit of early selection in relation to the target trait (i.e., $\mathrm{V}_{12}$, stem volume at age 12) was calculated as selection efficiency (eq. 10). This value was high already after 3 years $(0.80-0.83)$ and increased towards the target age, particularly for $D$ and $V$ that already at age 6 reached a value of 


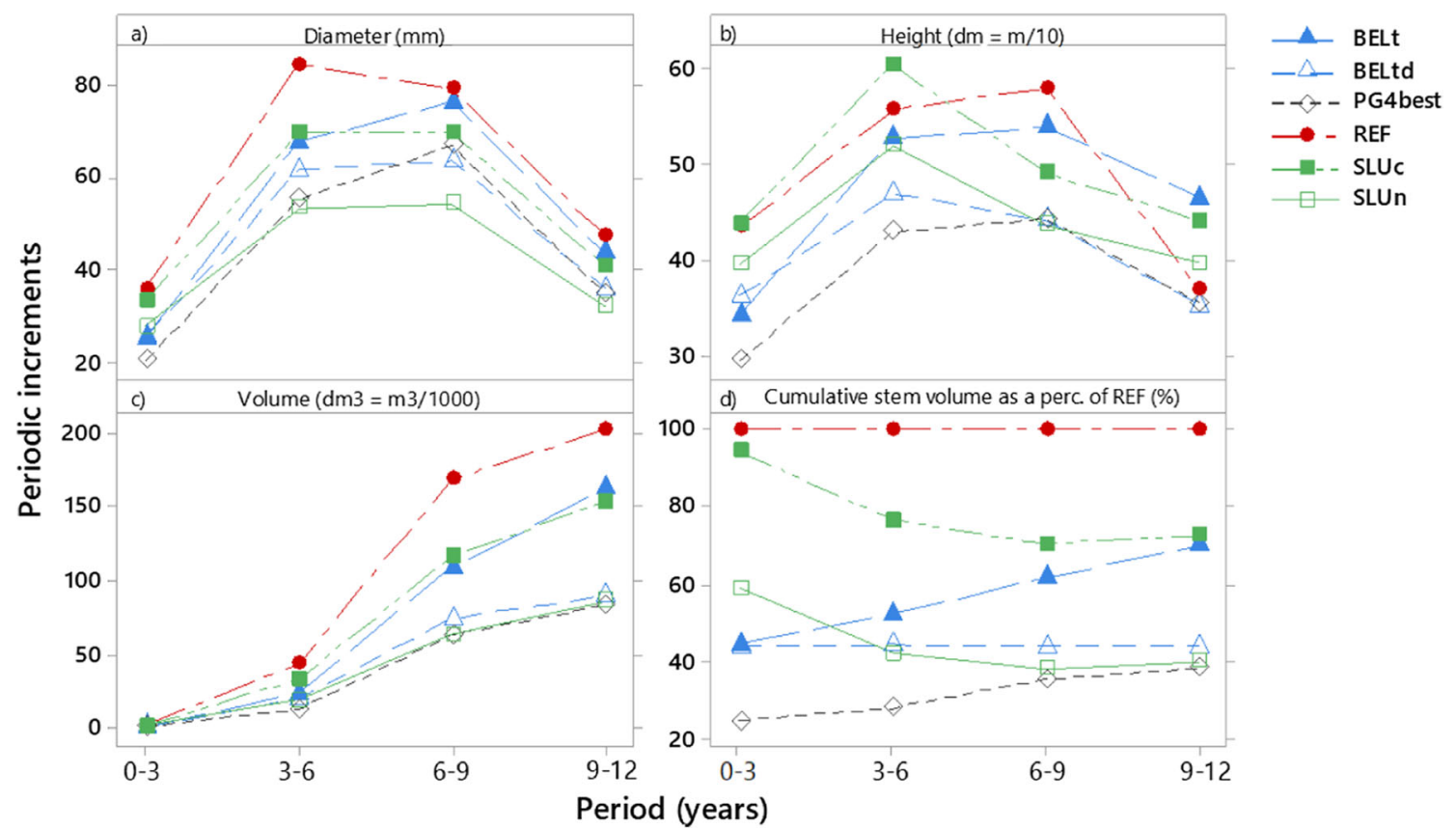

Fig. 1 The periodic diameter, height and stem volume (a, b, and $\mathbf{c})$ increment of poplar clones grown in southern Sweden. The standard error bars were omitted to increase the readability of the graph. The cumulative growths were presented as relative to REF clones (d). The

0.94 and 0.95 (Fig. 2). The selection efficiency calculated for the subset of 17 best performing clones had lower values initially (i.e., 0.59 for $\mathrm{D}_{3}$ ), increasing to 0.88 for $\mathrm{D}_{6}$ (Fig. 2). Thus, the precision of an early estimate increased substantially between age 3 and 6 years and was generally higher for $D$ and $V$ compared to $H$. However, despite a high selection efficiency at age 6 there were substantial changes in clonal rank within the subset of the 17 best clones between age 6 and 12 (Fig. 3). These changes were caused by differential growth development of different groups of clones (see SLUc and BELt in Fig. 1d) also reflected in lower correlation coefficients between cumulative and periodic growth traits (Table S3).

\section{Advantageous Stem Form and Branching Can Be Combined with High Growth Performance}

The stem straightness (STR) was $>2$ for most of the PG and the two REF clones, and $<2$ for the SLU and BELt clones. The score for branch angle (BRA) in the best producing clones was low (i.e., obtuse angle) except for "69.037/2" and "70.038/67" with higher scores of 2.4 and 2.3 respectively. Both branch thickness (BRTH) and branchiness (BRNS) were lowest for the SLU material (Table 4). The variance components of clonal effect $\left(\sigma_{G}^{2}\right)$ were moderate to strong, being largest (0.80) for BRNS (Tables 3 and 4). clones were grouped according to Table 1 except for PG4best representing the values of the four best performing PG clones with respect to stem volume at age $12\left(\mathrm{~V}_{12}\right)$

Crooks occurred frequently (26\%), but only $8 \%$ and $10 \%$ of the trees had discontinuous stems (loss of apical dominance in the tree crown) and forks (Table 5). Crooks and forks occurred usually at $50-60 \%$ of tree height at age 9 (Fig. S1, supplement) and were more frequently found on Swedish and Belgian material compared to the reference clones. The

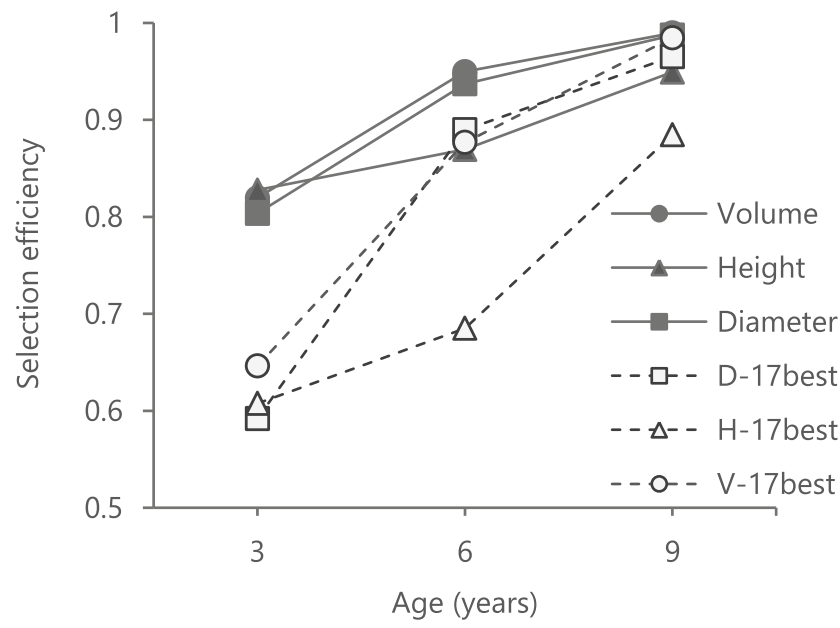

Fig. 2 The change of selection efficiency with time for diameter $(D)$, height $(H)$, and stem volume $(V)$ in the whole set of 32 clones (solid lines and filled symbols), and in the subset of 17 best clones (dashed lines, open symbols). The selection efficiency (eq. 10) expresses the precision of estimates of volume at age 12 years $\left(\mathrm{V}_{12}\right.$, Table 3$)$ by values of $D, H$, and $V$ at age 3,6 , and 9 years 


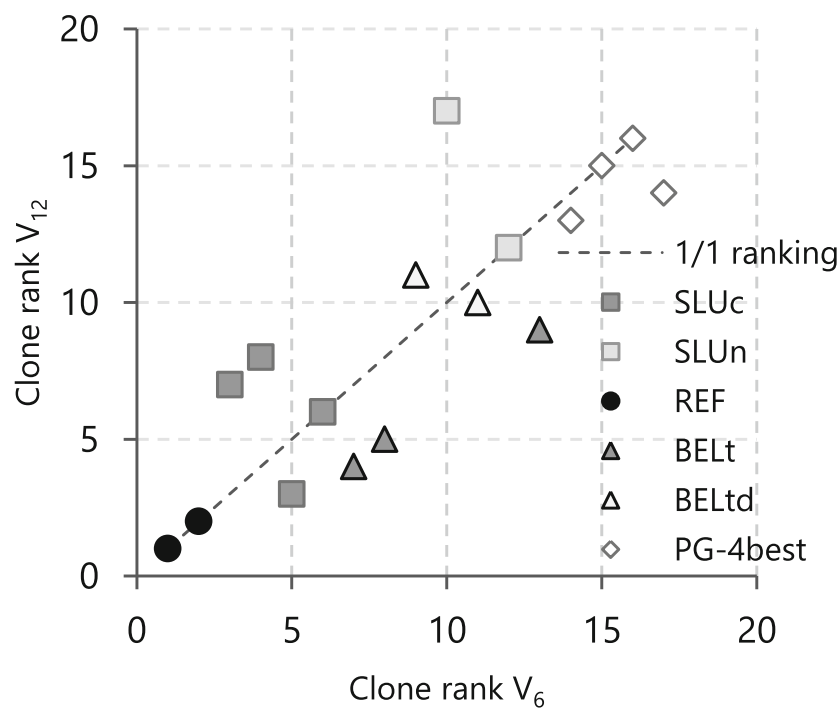

Fig. 3 The relationship between clone ranking for stem volume at age 12 and 6 years presented for the subset of 17 best growing poplar clones in the trial in southern Sweden. The dashed line represents the correlation coefficient of 1 between the ranks at different ages. The corresponding Pearson correlation coefficient between the two traits was 0.89 and the selection coefficient $\left(\mathrm{RS}_{y} / S_{x}\right)$ for $\mathrm{V}_{6}$ against $\mathrm{V}_{12}$ was 0.88 (see Fig. 2). Clonal rank for clones above the $1 / 1$ line decreases, while the opposite applies to the clones below the $1 / 1$ line

crooks were particularly often recorded on clones " 23.4 " (87\%), “70.038/67" (44\%), and "70.038/20" (58\%). Forks were most frequently found on Belgian $\mathrm{T} \times \mathrm{D}$ hybrid "70.045/1" (27\%), on two reference clones (20\% and 23\%) and on some PG clones.

The assessed stem form and branching characteristics were in general positively correlated to each other indicating that trees with thicker and denser branching had less straight stems with branches attached at a sharper angle. The same correlation pattern was also found within the two subsets of clones. Out of all the branching characteristics, particularly BRNS was negatively (low score for BRNS = less branchy appearance) correlated to volume and height. Also, BRTH and BRA were negatively correlated with growth, but significantly only for some of the growth variables. The correlations between STR and growth were not significant. Weak to moderate negative correlations of stem form and branching to growth indicated that desirable quality characteristics were generally found in better growing clones (Table S3 A and B).

\section{Larger Clonal Variation in Autumn Leaf Phenology than in Bud Burst}

The broad sense heritabilities $\left(\sigma_{G}^{2}\right)$ for phenology variables and canopy duration varied between 0.71 (CRC1) and 0.90 (BB3, Table 3). Bud burst (BB3) differed 13 days (Fig. 4g-i, values on $X$-axes) between the earliest ("PG5-2") and the latest flashing clone ("69.037/2"). Most of the clones reached BB3 within 5 days (i.e., doy 99-104) except the two BELtd clones reaching BB3 6 and 8 days later than any other clones. The clonal range for autumn leaf phenology traits varied from 35 (CRC1) to 52 (LS2) days. This range was strongly affected by a single clone ("FN3-20") and after its exclusion the range was between 24 (LS1) and 37 (LS2) days (Fig. 4a-c, values on $X$-axes). Canopy duration was calculated between BB3 and different autumn leaf phenology variables ranging from 163 days for "FN3-20" to 209 days for "OP-41" (Fig. 4d-e, values on $X$-axes calculated for number of days between BB3 and $\mathrm{CRC} 2$ ).

\section{Canopy Duration and Leaf Senescence, but Not Bud Burst, are Strongly Correlated to Growth}

Correlations among all analyzed variables were performed for (i) the whole set of 32 clones (Table S2 A and B), (ii) a subset of 17 best performing clones, and (iii) a subset containing only PG clones (Table S3 A and B). The same general pattern of positive, mostly significant, correlations between growth, leaf phenology, and canopy duration was present for the whole set and within the two subsets, where correlation coefficients were weaker and in many cases non-significant, particularly in the PG subset of clones. In contrast, growth and bud burst (BB3) were uncorrelated (Fig. 4). Coefficients for correlation of growth to autumn leaf phenology and canopy duration increased with age (Fig. 5). This trend was particularly consistent for both cumulative and periodic volume increment. The correlations between growth and autumn leaf phenology variables were stronger for the subset of 17 best clones compared to the PG subset (Fig. 5a, c). The strong correlations obtained between growth and phenology traits are presented by the slope of regression lines in Fig. 4a-e. For example, the values of diameter $\left(\mathrm{D}_{12}\right)$ and height $\left(\mathrm{H}_{12}\right)$ at age 12 increased by $3.5 \mathrm{~mm}$ and $2.8 \mathrm{dm}$ (i.e., $\mathrm{mm} / 100$ ) respectively for each day of prolonged growth until the leaf coloring stage (CRC2, i.e., doy for leaves turning yellow). The slope of regression lines of growth traits in relation to canopy duration (CADU) were almost identical (see equations presented in Fig. 4a-e).

\section{Hierarchical Cluster Analysis Visualizes the Links Between Genetic Background, Growth, and Quality Characteristics}

The resulting dendrogram from hierarchical cluster analysis was presented in Fig. 6. It divides the studied poplar material into two main branches with high performing clones in one branch (clusters 1, 2, 5, and 7) and all PG material including the SLUn and BELtd clones contained within the other branch. The four clusters of the first branch were separated mainly on the basis of cumulative and periodic growth for $D$ 
Table 4 The quality assessment scores for stem straightness, branch angle, branch thickness, and branchiness presented for five different poplar clone groups tested in southern Sweden

\begin{tabular}{|c|c|c|c|c|c|c|c|c|}
\hline Quality characteristic & Clone group & Mean & St dev & CoefVar & Range & Source & Var comp $\% / F$ value & $P$ value \\
\hline \multirow[t]{6}{*}{ Stem straightness (STR) } & BEL & 2.0 & 0.26 & 13.4 & 0.9 & Clone & 57.5 & 0.001 \\
\hline & $\mathrm{FN}$ & 2.1 & 0.22 & 10.6 & 0.5 & Row $(B)^{1}$ & 4.02 & 0.129 \\
\hline & PG & 2.2 & 0.41 & 18.8 & 1.6 & Column $(B)^{1}$ & 8.54 & 0.063 \\
\hline & REF & 2.2 & 0.18 & 7.9 & 0.5 & Error & 29.5 & 0 \\
\hline & SLU & 1.9 & 0.33 & 17.9 & 1.3 & $R_{\mathrm{adj}}^{2} \%$ & 80.84 & \\
\hline & All & 2.1 & 0.28 & 13.7 & 1.0 & & & \\
\hline \multirow[t]{6}{*}{ Branch angle (BRA) } & BEL & 2.1 & 0.33 & 15.9 & 1.2 & Clone & 61.9 & 0 \\
\hline & FN & 2.0 & 0.08 & 4.0 & 0.2 & Row $(B)$ & 2.3 & 0.197 \\
\hline & PG & 2.2 & 0.33 & 15.2 & 1.7 & Column $(B)$ & 1.7 & 0.376 \\
\hline & REF & 1.8 & 0.23 & 12.7 & 0.5 & Error & 33.5 & 0 \\
\hline & SLU & 1.7 & 0.27 & 15.5 & 0.8 & $R_{\text {adj }}^{2} \%$ & 75.6 & \\
\hline & All & 2.0 & 0.25 & 12.7 & 0.9 & & & \\
\hline \multirow[t]{6}{*}{ Branch thickness (BRTH) } & BEL & 1.9 & 0.44 & 23.2 & 1.6 & Clone & 60.3 & 0 \\
\hline & $\mathrm{FN}$ & 1.8 & 0.81 & 45.0 & 1.9 & Row $(B)$ & 0.6 & 0.426 \\
\hline & PG & 1.9 & 0.51 & 26.3 & 2.0 & Column $(B)$ & 11.4 & 0.047 \\
\hline & REF & 2.2 & 0.21 & 9.8 & 0.5 & Error & 27.7 & 0 \\
\hline & SLU & 1.3 & 0.34 & 26.3 & 1.0 & $\mathrm{CI}_{\text {slile }}$ & $30.7^{2}$ & 0 \\
\hline & All & 1.8 & 0.46 & 26.1 & 1.4 & $R_{\mathrm{adj}}^{2} \%$ & 85.94 & \\
\hline \multirow[t]{6}{*}{ Branch number, branchiness (BRNS) } & BEL & 2.3 & 0.45 & 19.7 & 1.7 & Clone & 80.1 & 0 \\
\hline & $\mathrm{FN}$ & 2.2 & 0.68 & 30.0 & 1.5 & Row $(B)$ & 6.72 & 0.03 \\
\hline & PG & 2.4 & 0.45 & 18.6 & 1.7 & Column $(B)$ & 0.52 & 0.384 \\
\hline & REF & 2.3 & 0.15 & 6.6 & 0.5 & Error & 12.63 & 0 \\
\hline & SLU & 1.2 & 0.35 & 28.1 & 1.1 & $\mathrm{CI}_{\text {slile }}$ & $41.44^{2}$ & 0 \\
\hline & All & 2.1 & 0.41 & 20.6 & 1.3 & $R_{\text {adj }}^{2} \%$ & 92.02 & \\
\hline
\end{tabular}

${ }^{1}$ The effects of plot random position in a row-column matrix within the block

${ }^{2} F$ value of covariance

and $H$ (Table 6). The division of clones into clusters is based on their proximity of cluster centroids with a strong tendency to reflect the common genetic origin of the clones. However, clone "23.4" (one-clone cluster 2) was separated from its halfsibs in cluster 1 based on growth characteristics, but also by the differential influence of its phenology (CRC2, BB3) and stem form (STR). Clustering of PG material provided more specific insights into this group of clones. Cluster 10, for example, contains the clones "PG2-22" and "PG5-5" with relatively weak diameter growth, but a high values for $\mathrm{H}_{12}$ and $\mathrm{zH}_{6-12}$. A low score for STR and BRNS in cluster 10 stands in a sharp contrast to the four highly producing clones (in terms of $\mathrm{V}_{12}$ ) of clones in cluster 9 that had poor scores for the two quality variables.

Cluster 3 contains the full-sibs " 44.7 " and "44.11" (SLUn) characterized by a considerable height growth and the most favorable STR and BRNS. The two BELtd hybrids were separated within cluster 4 by late bud burst, a relatively early autumn leaf coloring, and a poor height compared to diameter growth, i.e., low H/D value.

\section{Discussion}

In this study, we compared two commercial $P$. maximowiczii $\times$ trichocarpa clones with new, potentially promising, material of $P$. trichocarpa and $P$. trichocarpa $\times$ deltoides bred (SLU) or selected (BEL) specifically for Swedish photoperiod and climate conditions. This clone evaluation presents results after 12 years of growth, whereas a majority of comparable studies on poplars are from younger trials. Growth data from 3-year periods allowed us to estimate agedependent correlation coefficients for growth performance, and to establish correlations between single-year phenological observations and growth at different ages. Growth performance was additionally emphasized by using 6-year periodic increments $\left(\mathrm{zD}_{6-12}\right.$ and $\left.\mathrm{zH}_{6-12}\right)$ in a hierarchical cluster analysis. The correlation analysis performed for slower growing progenies from British Columbia revealed that some general correlation patterns present in the material of broader geographic origin can also be observed within a single geographic origin 
Table 5 Occurrence of stem deviations in 9-year-old poplar clones tested in Arlösa, southern Sweden. For definition of clone groups see Table 1

\begin{tabular}{|c|c|c|c|c|c|c|c|c|}
\hline $\begin{array}{l}\text { Characteristics of stem } \\
\text { deviations }\end{array}$ & $\begin{array}{l}\text { Clone } \\
\text { group }\end{array}$ & $\begin{array}{l}\text { Total } \\
\text { count }\end{array}$ & $\begin{array}{l}N \text { of trees (\% of clone } \\
\text { group count) }\end{array}$ & $\begin{array}{l}\text { Mean height }(\mathrm{dm}),(\% \text { of tree } \\
\text { height at age } 9)\end{array}$ & $\begin{array}{l}\text { St. dev mean } \\
\text { height }(\mathrm{dm})\end{array}$ & & $\begin{array}{l}\text { Min height } \\
(\mathrm{dm})\end{array}$ & $\begin{array}{l}\text { Max height } \\
(\mathrm{dm})\end{array}$ \\
\hline \multirow{6}{*}{$\begin{array}{l}\text { Discontinuous stem in } \\
\text { tree crown }\end{array}$} & BEL & 88 & $4(4.5)$ & $69(56)$ & 38.7 & & 12 & 96 \\
\hline & $\mathrm{FN}$ & 22 & $2(9.1)$ & $76(70)$ & 1.41 & & 75 & 77 \\
\hline & PG & 301 & $24(8.0)$ & $74(68)$ & 17.17 & & 36 & 106 \\
\hline & REF & 32 & $4(12.5)$ & $119(68)$ & 13.92 & & 105 & 131 \\
\hline & SLU & 110 & $7(6.5)$ & $106(72)$ & 17.8 & & 78 & 124 \\
\hline & All & 553 & $41(7.9)$ & $83(68)$ & 18.3 & & 50 & 109 \\
\hline \multirow[t]{6}{*}{ Crotches } & BEL & 88 & $29(33.0)$ & $73(52)$ & 22.75 & & 28 & 124 \\
\hline & $\mathrm{FN}$ & 22 & $4(18.2)$ & $59(52)$ & 11.8 & & 51 & 76 \\
\hline & PG & 301 & $30(10.0)$ & $57(49)$ & 21.54 & & 19 & 101 \\
\hline & REF & 32 & 7 (21.9) & $96(58)$ & 11.75 & & 79 & 111 \\
\hline & SLU & 110 & $38(34.5)$ & $78(53)$ & 19.45 & & 45 & 129 \\
\hline & All & 553 & $108(25.9)$ & $71(52)$ & 20.13 & & 35.64 & 116.75 \\
\hline \multirow[t]{6}{*}{ Forks } & BEL & 88 & $8(9.1)$ & $74(57)$ & 12.98 & & 55 & 94 \\
\hline & FN & 22 & $0(0)$ & & & $*$ & $*$ & $*$ \\
\hline & PG & 301 & $18(6.0)$ & $62(55)$ & 21.75 & & 25 & 106 \\
\hline & REF & 32 & 7 (21.9) & $91(52)$ & 19.28 & & 54 & 112 \\
\hline & SLU & 110 & $7(6.4)$ & $91(57)$ & 17.31 & & 65 & 118 \\
\hline & All & 553 & $40(9.5)$ & $74(55)$ & 18.79 & & 43 & 107 \\
\hline
\end{tabular}

(Table S3). Fast growth and a substantial phenological variation provided good prerequisites to reveal correlation patterns among growth, phenology, and branching traits.
In addition, the analysis of variations in stem form and branching represents an important, but rarely described aspect of the selection of poplar clones.

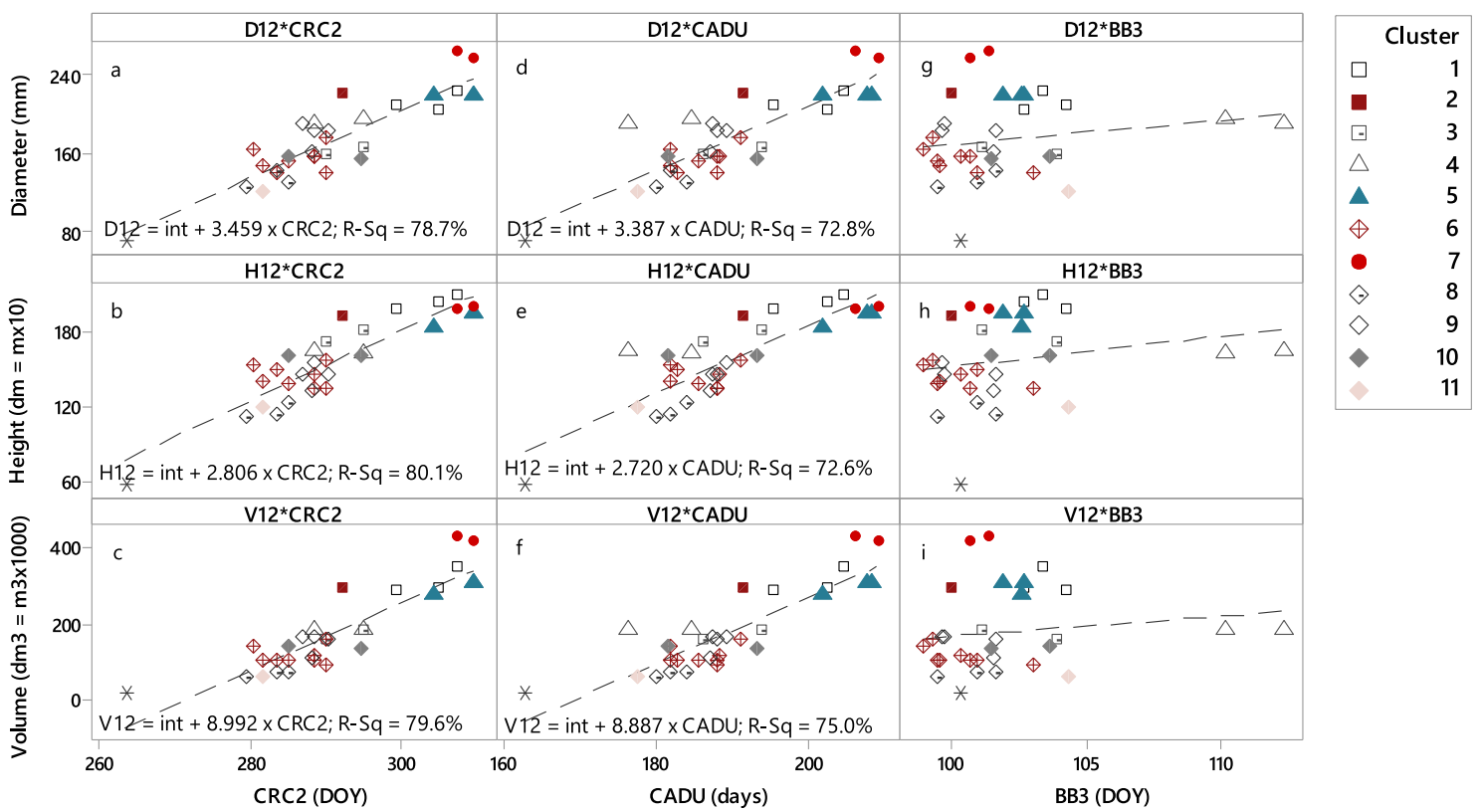

Fig. 4 The genotypic values for timing and range of leaf coloration (CRC2), canopy duration (CADU), and bud burst (BB3) of poplar clones grown in southern Sweden as related to cumulative diameter $\left(D_{12}\right)$, height $\left(\mathrm{H}_{12}\right)$, and stem volume $\left(\mathrm{V}_{12}\right)$ at age 12 years. Dashed line represents linear regression line of growth traits as related to the clonal genotypic values for $\mathrm{CRC} 2$, CADU, and BB3. The slope of increasing $Y$ over $X$ is provided in equations for $\mathrm{CRC} 2$ and $\mathrm{CADU}$. Clones were grouped according to clustering from the multivariate analysis presented in Fig. 6 and Table 6 


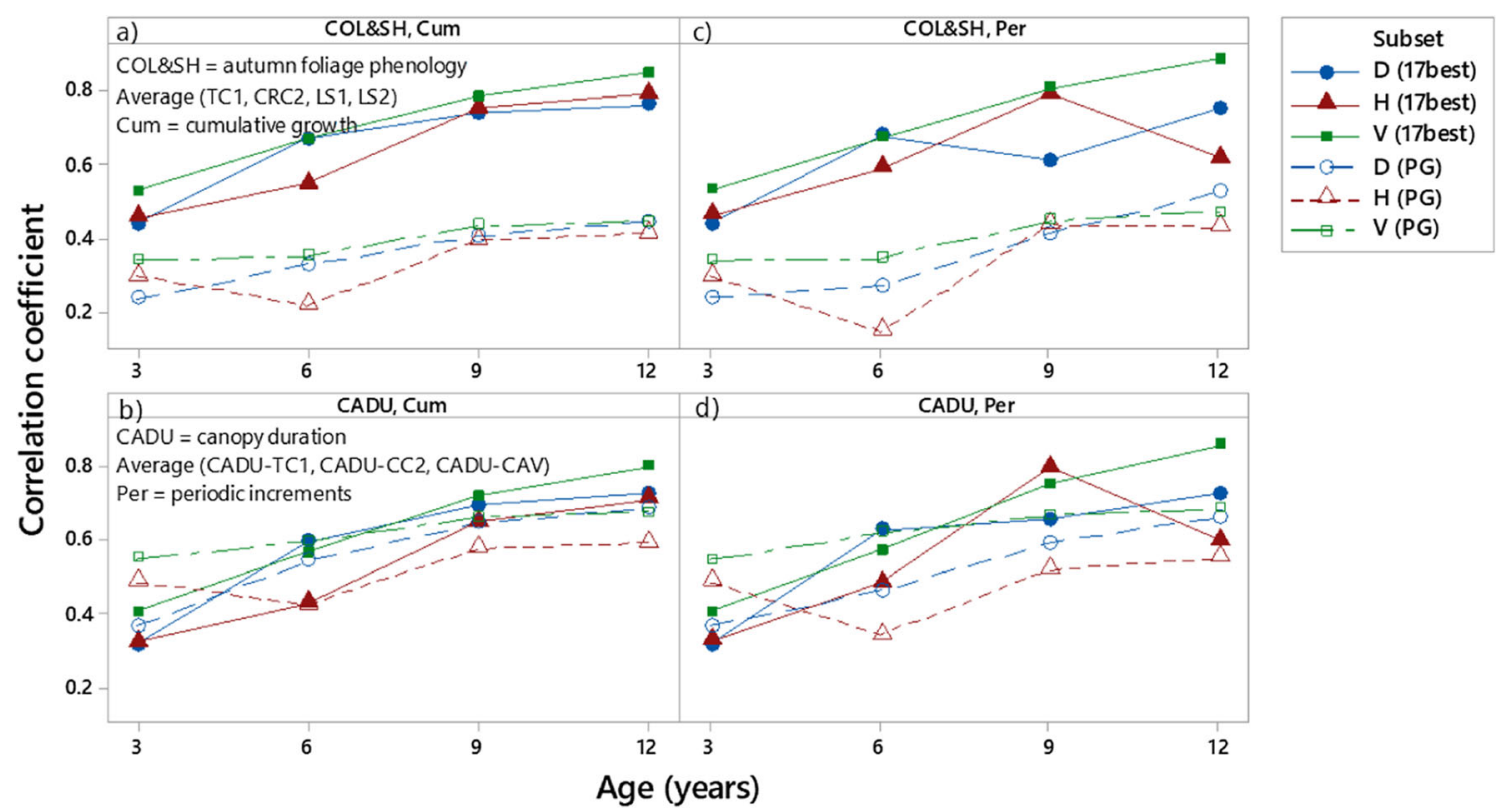

Fig. 5 The change with time of correlation coefficients between growth and phenology. Cumulative growth ("Cum") and periodic growth increment ("Per") were shown in separate panels in relations to average autumn leaf phenology ("COL\&SH") and canopy duration ("CADU”). The coefficients for correlations with periodic increments ("Per") at 3, 6,

\section{High Heritability Values and Strong Age-Age Correlations Increase the Precision of Early Clonal Selection}

First, it needs to be stressed that the high broad sense heritability values $\left(\sigma_{G}^{2}\right.$, hereafter "heritability") obtained in this
9 , and 12 years represent the periods $0-3,3-6,6-9$, and $9-12$ years. The subsets of the 17 best clones ("17best") and PG clones ("PG") were shown separately. COL\&SH is the average of correlation coefficients to TC1, CRC2, LS1, and LS2. CADU is the average to CADU-TC1, CADU-CRC2, and CADU-CAV

study for the growth traits were likely biased upward (i.e., overestimated). For instance, (i) heritability obtained from single-site trials lacks separation between genetic and genetic $x$ environment effects present in the studies where the trial design includes replications on several locations. Thus, in this study the potential genetic $\times$ environment variance was

Table 6 Cluster centroids (CC) and mean cluster values for the eight variables included in hierarchical cluster analysis of 31 poplar clones grown in southern Sweden

\begin{tabular}{|c|c|c|c|c|c|c|c|c|c|c|c|}
\hline Variable & Cluster1 & Cluster2 & Cluster3 & Cluster4 & Cluster5 & Cluster6 & Cluster7 & Cluster8 & Cluster9 & Cluster10 & Cluster11 \\
\hline $\mathrm{D}_{12}(\mathrm{CC})$ & 0.90 & 1.29 & -0.31 & 0.36 & 1.10 & -0.67 & 2.16 & -1.24 & 0.01 & -0.58 & -1.54 \\
\hline $\mathrm{D}_{12}(\mathrm{~mm})$ & 212 & 219 & 161 & 191 & 218 & 152 & 260 & 131 & 179 & 153 & 119 \\
\hline $\mathrm{H}_{12}(\mathrm{CC})$ & 1.52 & 1.13 & 0.58 & 0.10 & 1.04 & -0.58 & 1.33 & -1.54 & -0.53 & 0.01 & -1.46 \\
\hline $\mathrm{H}_{12}(\mathrm{dm}=\mathrm{m} \times 10)$ & 204 & 193 & 177 & 163 & 190 & 143 & 199 & 116 & 145 & 161 & 118 \\
\hline $\mathrm{zD}_{6-12}(\mathrm{CC})$ & 0.60 & 1.47 & -0.49 & 0.05 & 1.35 & -0.47 & 1.70 & -1.32 & 0.10 & -0.28 & -1.94 \\
\hline $\mathrm{zD}_{6-12}(\mathrm{~mm})$ & 107 & 119 & 91 & 99 & 118 & 89 & 123 & 79 & 100 & 94 & 70 \\
\hline $\mathrm{zH}_{6-12}(\mathrm{CC})$ & 1.18 & 0.32 & 0.16 & -0.12 & 1.54 & -0.45 & 1.06 & -1.77 & -0.20 & 0.36 & -1.67 \\
\hline $\mathrm{zH}_{6-12}(\mathrm{dm}=\mathrm{m} \times 10)$ & 98 & 86 & 84 & 80 & 103 & 75 & 96 & 56 & 79 & 86 & 58 \\
\hline CRC2 (CC) & 1.21 & -0.02 & 0.01 & -0.08 & 1.63 & -0.67 & 1.71 & -1.03 & -0.42 & -0.26 & -1.12 \\
\hline CRC2 (doy) & 304 & 292 & 293 & 292 & 308 & 286 & 309 & 283 & 288 & 290 & 282 \\
\hline BB3 (CC) & 0.49 & -0.71 & 0.16 & 3.16 & 0.12 & -0.60 & -0.35 & -0.46 & -0.49 & 0.17 & 0.78 \\
\hline BB3 (doy) & 103 & 100 & 102 & 111 & 102 & 100 & 101 & 101 & 101 & 103 & 104 \\
\hline STR (CC) & -0.70 & 0.69 & -1.43 & -0.16 & -0.61 & -0.26 & 0.49 & 1.02 & 1.63 & -0.79 & -0.51 \\
\hline STR (score) & 1.9 & 2.3 & 1.7 & 2.0 & 1.9 & 2.0 & 2.2 & 2.4 & 2.5 & 1.9 & 2.0 \\
\hline BRNS (CC) & -1.71 & -1.56 & -1.70 & 0.30 & -0.13 & 0.33 & 0.03 & 0.97 & 1.13 & 0.07 & -0.37 \\
\hline BRNS (score) & 1.2 & 1.3 & 1.3 & 2.3 & 2.1 & 2.3 & 2.2 & 2.7 & 2.8 & 2.2 & 2.0 \\
\hline
\end{tabular}




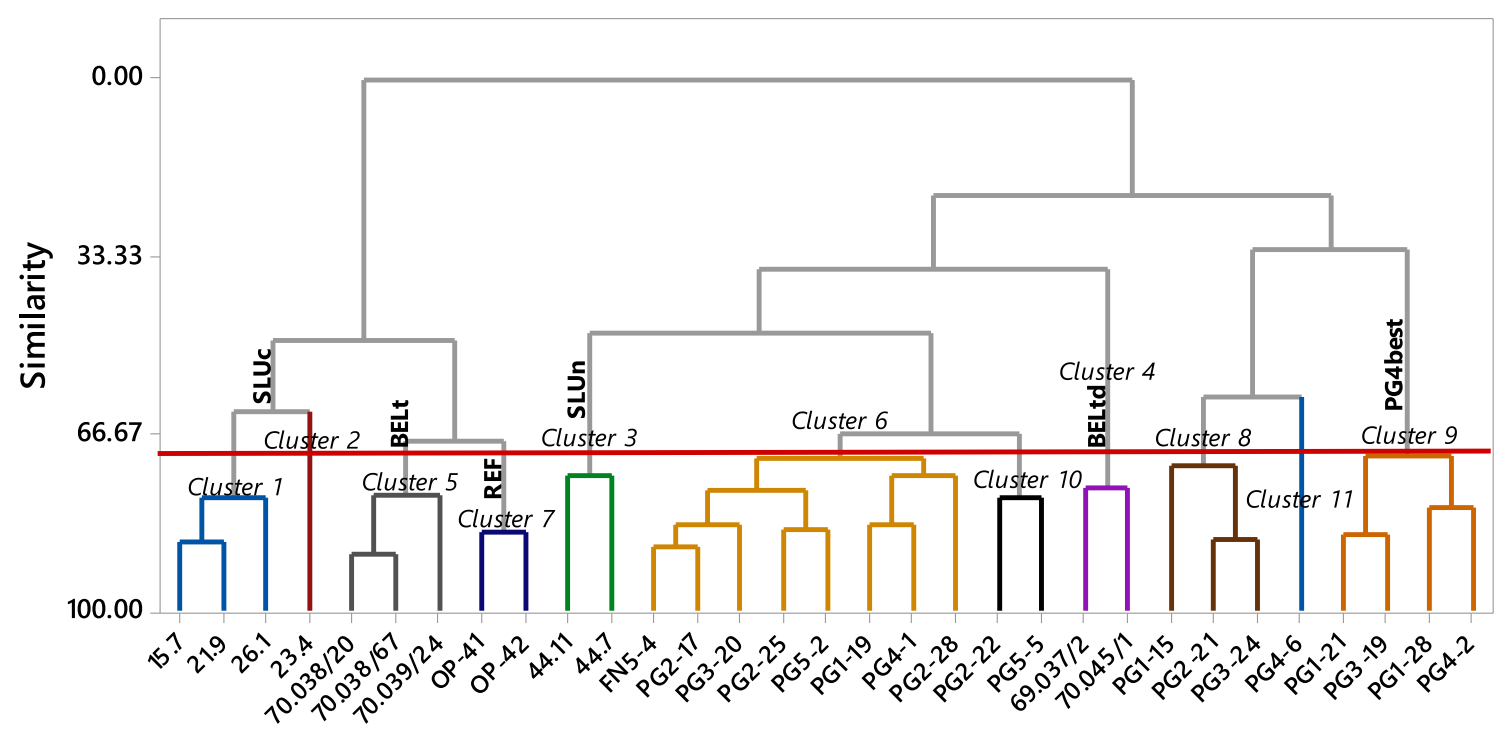

Fig. 6 Dendrogram of hierarchical cluster analysis performed using eight traits for 31, 12-year-old poplar clones, grown in southern Sweden. Eleven clusters were cut-off at similarity 70 (horizontal line) are indicated on dendrogram branches, as well as the six groups of clones compared for growth and stem and branching characteristics. The analysis was

confounded with genetic variance in the numerator of eq. 6 . For this reason, more accurate estimates of heritability require larger material, replicated in several edaphic and climatic environments where poplars are intended to be grown [43]. Other potential sources of upward bias were (ii) relatively homogeneous and favorable growing conditions allowing the full expression of genetic potential reducing the spurious environmental effects; (iii) large heterogeneity of tested material; (iv) possible competition effects, which we tried to accommodate for by using competition indices as covariates; (v) exclusion of genetic relatedness of clones as a term in the model; and (vi) the use of line plot values as entries in the analysis, thus disregarding the variation present among individual trees within line plots. The heritabilities calculated on the basis of line plots are difficult to compare with individual tree heritabilities but are useful for the purpose of clonal selection as it was applied in the present study [44]. We did not use family terms in the model due to a complexity already imposed by the inclusion of raw-column matrices within blocks as well as the competition indices.

In this study, the heritability values $\left(\sigma_{G}^{2}=0.74-0.87\right)$ for cumulative growth $(D, H, V)$ were similar or higher than values reported from other single-site Populus trials. However, some authors reported repeatability of clonal means as a measure of heritability $\left(R_{c}\right.$, eq. 8 , Table 3$)$. The $R_{c}$ values calculated for growth variables presented in Table 3 were higher $(0.81-0.97)$ than the corresponding values (0.65-0.91) reported from two 3year-old Lithuanian poplar trials planted with more than a 100 clones of different origin [18]. Heritabilities similar or lower $(0.38-0.89)$ to those obtained in our study were reported from

\section{Clones}

performed based on two cumulative growth variables $\left(D_{12}, H_{12}\right)$, two periodic growth variables for age $6-12\left(\mathrm{zD}_{6-12}, \mathrm{zH}_{6-12}\right)$, two phenology variables (BB3, CRC2), and two variables describing stem form (STR) and branchiness (BRNS)

two Swedish poplar trials, 10 and 14 years old [23, 24], as well as from several, $8-9$ years old, hybrid aspen trials $(0.23-0.63)$ [42]. For $D$ and $H$, heritability increased between age 6 and 9 years, while staying constant for $V$ after the initial increase between age 3 and 6 years (Table 3). Other authors compared heritabilities for cumulative growth variables in conifer species reporting either changing or approximately constant values with increasing tree age [45-48]. Stener and Karlsson [42] accounted the increase of heritability values with age in hybrid aspen trials exclusively to competition effects. On the other hand, heritabilities of periodic increments $(\mathrm{zD}$ and $\mathrm{zH})$ in our study decreased with increasing age, while $\mathrm{zV}$ remained constant after an initial increase between age 3 and 6 years. If competition was the main source of increasing heritability for a cumulative growth trait, we would have expected this to be reflected also in increasing heritabilities of periodic volume increments. This was not the case in our analysis, and one possibility is that the competition effects for volume increments were compensated for by competition indices, SLL (sum of line lengths) and NP (neighbor plots). Brodie and DeBell [40] found competition indices particularly useful as a tool for reranking the clonal performance from mixed clonal plots to better fit the expected results in monoclonal plots. The linear character of zD, for example, implies that similar zD corresponds to different $\mathrm{zV}$ in the trees of different sizes. Consequently, a better estimate of heritability for periodic clonal growth should be achieved by analyzing $\mathrm{zD}^{2}$ or, as in our cases, the stem volume increment $(\mathrm{zV})$, for which heritability values did not decrease in our study, but remained constant for the period 312 years (Table 3 ). 
A higher heritability of a trait implies a better precision of clonal estimates and indicates good possibilities for an effective clonal selection [33]. A successful early selection depends also on traits at selection age being strongly correlated with the selection traits at the target age [43, 44]. In our case, with $\mathrm{V}_{12}$ as a target trait, both these components increased with age (i.e., $\mathrm{D}_{9}$ and $\mathrm{V}_{12}$ were better correlated than $\mathrm{D}_{3}$ and $\mathrm{V}_{12}$ ), but a relatively high selection efficiency could be reached already at age 6 (Fig. 2). Diameter appeared to be a better early selection criterion than height, which can also be explained by its stronger allometric influence on volume compared to height [49]. The most important implication of a high selection efficiency should be contained in a relatively high accuracy at an early clonal selection. However, the correlations of clonal ranks for volume between age 6 and 12 show that substantial changes occurred during this period despite high age-age correlations and correlation efficiency. Clone "70038/24," for example, improved its rank from 13 to 9 between age 6 and 12, but was a top-three clone with regard to $\mathrm{zD}_{9-12}$ and $\mathrm{zH}_{9-12}$. Also, two other BELt clones gained on SLUc clones during this period. Thus, it could be argued that an early clonal selection in this type of trials needs to target a larger proportion of the tested material and is most effective as a mean to select sets of clones for production trials and pilot plantations, rather than single out very few clones to be deployed commercially on a large scale.

The clonal variance component $\left(\sigma_{G}^{2}\right)$, i.e., heritability, of spring and autumn phenology traits was high in the present study, being highest for BB3, CRC2, and LS2. CRC2 and LS2 were similarly defined in the recent study on $P$. trichocarpa in central Sweden [50] showing also the highest heritability among other traits of autumn leaf phenology. Medium to high heritability values obtained for stem form and branching characteristics suggest that these traits are strongly genetically determined and can be selected for in order to improve the value of produced poplar biomass. Similar characteristics of stem form and branching were reported in 7-year-old poplar trials in southern Sweden [24], with heritability values between 0.35 for branch thickness and 0.59 for the number of branches. The corresponding values in this study were 0.60 and 0.80 (branchiness). Somewhat lower heritabilities $(0.21-0.29)$ for these characteristics were reported in a study of 10-year-old hybrid aspen [42], while Karlsson et al. [23] obtained values of 0.50 and 0.30 for straightness and branching type in 14year-old poplar trials with a set of clones grown in central Europe.

\section{Correlations and Hierarchical Cluster Analysis}

Our study confirmed the positive correlations between autumn phenology and growth reported in other studies [18, 29, 33, 51-55]. High heritability values for both growth and autumn phenology traits indicate that there is enough variability to adapt poplars to photoperiods at higher latitudes in Sweden. If selection is entirely based on growth, there will be a tendency to deploy clones that run increased risk of frost damage if planted at harsher localities or higher latitudes. The selection for an earlier autumn phenology, on the other hand, will tend to decrease biomass production. As poplar plantations are based on the qualities of selected individual genotypes, the selection can be directed to the outliers from these general trends. Thus, to select suitable clones for higher latitudes, we would need to look for genotypes with high performance under shorter growing seasons or clones that partly can compensate an earlier autumn phenology with an earlier bud burst in spring. Based on our results, one such clone could be SLU:s "23.4," which had 15 days earlier leaf coloration and shedding compared to "OP-42" (Fig. 4). This clone still produced 69\% of the stem volume of "OP-42" by the age 12 years and performed equally well as other SLU and BEL clones with autumn phenology similar or delayed compared to "OP-42."

Contrary to autumn phenology the variation in spring phenology was lower and was not correlated with growth (Fig. 4). A tendency of weak negative correlations were found within "PG" subset indicating that PG clones with an early bud burst tended to perform better. Pliura et al. [18] reported an early bud burst to have significantly positive effect on poplar growth in a large material covering several poplar species and hybrids. Also, Yu et al. [56] found earlier-flushing hybrid aspen to achieve a better growth compared to a local and laterflushing aspen material. Other studies mostly report weak or non-existing direct correlations between bud burst and growth performance [32, 54].

In the present study, the length of clonal canopy duration (i.e., effective growth season length) can only be regarded as hypothetical as it was calculated on bud burst and autumn leaf phenology from different years. In addition, the year of leaf phenology screening (2018) was unusual due to an extremely warm summer, which might have affected leaf phenology, exaggerating the differences between vigorous and more suppressed clones. Thus, the strong relationships between autumn phenology, canopy duration, and growth (Fig. 4) need to be considered in the light of the possibility that the timing of autumn leaf phenology did not only reflect the phenological trait, but might also have been affected by the tree (clonal) vigor in 2018. More frequent inventories of phenological traits are necessary to reveal the true strength of these correlations. However, the relative timing of phenology events in Populus seems to be reasonably stable across different years and sites. This is particularly true for bud burst [34], while reports on relative stability of autumn phenology vary in this respect [33, $56,57]$. We assumed that the projected length of canopy duration for a clone may hold for correlations with cumulative and periodic growth, i.e., general trends, and not for modeling of biomass growth in any particular year. Positive correlations 
with growth were the overall trend for canopy duration also present in the two subsets of clones (Fig. 5). Thus, our results confirm previous reports of moderate to strong correlations between growth and canopy duration (length of seasonal growth) in Populus [18, 32, 58-61]. Correlation coefficients between cumulative growth, canopy duration, and autumn leaf phenology increased with time in our data (Fig. 5), which might be related to the cumulative nature of this growth trait. The increase of correlation coefficients of periodic increments can have several different causes such as increased competition, an improved ability with age to express genetic potential or the cumulative effect of previous biomass growth that was not accounted for in the mixed models. The increase of correlation coefficients between autumn phenology respective canopy duration and $\mathrm{zV}$ was much steeper for the full set of 32 clones compared to the subset for 17 best clones, which suggests that the composition of the material plays a substantial role for modeling of trends in this type of correlations. For the subset of PG clones, i.e., within the material of a single geographic origin, these correlations confirm that delayed autumn phenology provide a competitive advantage with regard to growth. It is thus expected that there will be a selection pressure at lower latitudes or a in a changed climate to favor genotypes adapted to warmer autumns allowing for prolonged period of growth. The lack of significant correlations between bud burst and autumn phenology indicates that different sets of genes regulate these traits, and that they may be bred for separately [43]. Different stages of leaf senescence were all well correlated in our data set and also correlated with canopy duration. It has been shown earlier that clones with late start in spring, initiated on high temperature sums [18], may lose a substantial part of growing season, which must be regarded disadvantageous at higher latitudes.

The correlations between growth, stem form, and branching characteristics were presented in Table S2 and S3. Initially, diameter $\left(\mathrm{D}_{3}\right)$ and the branching scores were negatively and significantly correlated suggesting that trees with more favorable branching characteristics grew better. By the age 12 years, however, these correlations weakened, while the correlations between height and branching stayed negative and significant throughout the 12-year period. It can be expected that an extensive branchiness or thick branches may have positive effect on diameter development. The quality aspects have been studied more often in other species where discordances between diameter growth and quality characteristics are often handled by putting additional emphasize on height growth [43]. This, presumably unfavorable correlation between growth and quality imposes additional difficulties on defining poplar ideotypes, with imperative to satisfy a broad spectrum of possible end uses. However, our data clearly confirmed that height growth and stem form (STR) were negatively affected by branch number (BRNS) and thickness (BRTH), suggesting that the selection for biomass performance needs to be balanced by quality characteristics.
As selection of suitable clones is dependent on growth, climate adaptation, and quality traits, we used multivariate analysis for grouping and evaluating clones. The hierarchical clustering is useful for selecting clones with similar characteristics, provides an overview of the material and represents a valuable aid for the decisions about further testing of clones or their deployment in pilot plantations. The clusters can also be useful for the composition of clonal mixtures to be deployed commercially, particularly when site-specific studies on clonal performance are not yet available. Deployment of clones in mixtures is regarded as advantageous in terms of risk avoidance and ecological services and has been applied in Sweden for both hybrid aspen and poplars [62]. Hierarchical clustering is more efficient when underlying traits are characterized by high heritability and clear correlation patterns. In our case, four out of eight variables characterized growth, a deliberate choice to emphasize growth where cumulative growth represented a feature of overall clonal performance, and the periodic increment at age 6-12 years characterizing clonal development after the anticipated time for the first selection at the age of 6 years. The use of bud burst and leaf coloring as phenological variables is governed by their high heritabilities (i.e., large variation in the studied material) and importance in the delimitating the length of canopy duration. Stem straightness and branchiness, on the other hand, have shown high heritability values in this study and are important for the characterization of clones and their suitability for use in different types of growing systems.

The results of present study implicate a superior performance of the two commercial clones "OP-41" and "OP-42" (Cluster 7). P. maximowiczii $\times$ trichocarpa hybrids have been frequently reported as high performing in other studies from central and northern Europe and in comparison with the material of varying origin $[17,18,33,37,63-65]$. These hybrids are undoubtedly of interest for northern Europe and should be included in the future breeding programs targeting geographical regions at high latitudes. The BELt and SLUc clones performed less, but can be of interest for further testing in southern Sweden (particularly BELt clones, cluster 5) and as an alternative at latitudes $57-59^{\circ} \mathrm{N}$ (cluster 1). Clone "23.4" was separated into a single-clone cluster (cluster 2) due to its distinct characteristics of high diameter increment, lower height increment in the period between age 6 and 12 years, earlier autumn phenology, earlier bud burst, and less advantageous stem form (Fig. 6, Table 6). Thus, clone "23.4" belongs to the branch of high producing clones (SLUc, BELt, and REF clones; Fig. 6) while phenologically having potential to be transferred to the north at much lower risk compared to REF clones. In general, SLUc and BELt clones had more favorable stem form and branching traits compared to REF clones at the expense of productivity. However, high-producing clones with smaller crowns, such as "21.9," may potentially be interesting for growing systems established with denser initial planting distances and thinning schemes. The multivariate 
analysis was also useful for structuring PG clones, which potentially can be of interest in breeding for higher latitudes. For example, clones belonging to cluster 9 were best in terms of volume growth, but are also characterized unfavorable values for STR and BRNS. Thus, extensive branching may have contributed to overestimate the measured stem diameter and volume while signaling decreased value related to harvest and industrial processing of biomass. Contrary, the clones "PG222 " and "PG5-5" separated within cluster 10 seem to be good candidates for inclusion in germplasm of Swedish poplar breeding population, as they have straight stems, relatively thin branches and the best height increment among PG material.

\section{Conclusions}

- The commercial clones "OP-42" and "OP-41" have shown superior performance, but unfavorable stem form and branching compared to the Swedish and Belgian P. trichocarpa clones selected for this study.

- Some Swedish P. trichocarpa clones demonstrate potential to be deployed at higher latitudes, where growth of "OP-42" implies an increased economic risk.

- Late autumn phenology and longer canopy duration correlate positively with productivity. Thus, the selection of clones for deployment at higher latitudes needs to be based on their relative phenological characteristics.

- Stem straightness and height growth are negatively influenced by extensive branching.

- Hierarchical cluster analysis provides a valuable tool for clonal evaluation based on growth, phenology, stem form, and branching characteristics. The material is separated in clusters that reflect the origin and parentage of the material, while providing a visual overview of differences and similarities among the material. The method is useful for decision making with regard to clonal deployment and building up a poplar breeding population for northern latitudes.

Supplementary Information The online version contains supplementary material available at https://doi.org/10.1007/s12155-020-10210-y.

Acknowledgements This study was founded by SweTree Technologies AB, the Swedish Research Council (FORMAS) as a part of the Climate Adapted Poplar (CLAP) project (942-2016-20001), and The Swedish Energy Agency as a part of the project Cotton substitute and biofuel from fast-growing deciduous tree species (45903-1). We are greatly thankful to Ulf Johansson and his crew at the SLU:s Tönnersjöheden research station for their excellent work on the establishment, management, and measurement of the poplar trial in Arlösa. We also thank Marijke Steenackers from the Research Institute for Nature and Forest, Brussels (INBO) for providing the valuable information on the origin and pedigree of clones bred in Belgium.
Authors' Contributions Almir Karacic: developed the concept and methodology, analyzed the data, and wrote the original draft, reviewed and edited final manuscript. Anneli Adler: funding acquisition, trial management, data acquisition, and reviewing the manuscript. Martin Weih: funding acquisition, reviewing, and editing the manuscript. Lars Christersson: funding acquisition, conceptualization, and acquisition of material used in the study, the project initiation, reviewing, and editing.

Funding Open access funding provided by Swedish University of Agricultural Sciences. 1. The Swedish Research Council (FORMAS) as a part of the Climate Adapted Poplar (CLAP) project (942-2016-20001),

2. The Swedish Energy Agency as a part of the project Cotton substitute and biofuel from fast-growing deciduous tree species (45903-1).

3. SweTree Technologies AB

Data availability The data are available from the corresponding author upon request.

\section{Compliance with Ethical Standards}

Conflict of Interest The authors declare that they have no competing interests.

Open Access This article is licensed under a Creative Commons Attribution 4.0 International License, which permits use, sharing, adaptation, distribution and reproduction in any medium or format, as long as you give appropriate credit to the original author(s) and the source, provide a link to the Creative Commons licence, and indicate if changes were made. The images or other third party material in this article are included in the article's Creative Commons licence, unless indicated otherwise in a credit line to the material. If material is not included in the article's Creative Commons licence and your intended use is not permitted by statutory regulation or exceeds the permitted use, you will need to obtain permission directly from the copyright holder. To view a copy of this licence, visit http://creativecommons.org/licenses/by/4.0/.

\section{References}

1. Weih M (2004) Intensive short rotation forestry in boreal climates: present and future perspectives. Can J For Res 34(7):1369-1378. https://doi.org/10.1139/X04-090

2. Rytter L, Johansson T, Karacic A, Weih M (2011) Orienterande studie om ett svenskt forskningsprogram för poppel. Arbetsrapport / Skogforsk (1404-305X). Uppsala

3. Karacic A, Verwijst T, Weih M (2003) Above-ground woody biomass production of short-rotation populus plantations on agricultural land in Sweden. Scand J Forest Res 18(5):427-437. https:// doi.org/10.1080/02827580310009113

4. Johansson T, Karacic A (2011) Increment and biomass in hybrid poplar and some practical implications. Biomass Bioenergy 35(5): 1925-1934. https://doi.org/10.1016/j.biombioe.2011.01.040

5. Weih M, Karacic A, Munkert H, Verwijst T, Diekmann M (2003) Influence of young poplar stands on floristic diversity in agricultural landscapes (Sweden). Basic Appl Ecol 4(2):149-156. https://doi. org/10.1078/1439-1791-00157

6. Adler A, Karacic A, Weih M (2008) Biomass allocation and nutrient use in fast-growing woody and herbaceous perennials used for phytoremediation. Plant Soil 305(1-2):189-206. https://doi.org/10. 1007/s11104-008-9551-2

7. Schreiner EJ, Stout AB (1934) Description of ten new hybrid poplars. Bull Torrey Bot Club 61(8):449-460 
8. Schreiner EJ (1974) Early distribution of the Northeastern hybrid poplars. Paper presented at the 22nd Northeastern Forest Tree Improvement Conference

9. Schreiner EJ (1972) Procedure for selection of hybrid poplar clones for commercial trials in the northeastern region. Paper presented at the 19th Northeastern Forest Tree Improvement Conference

10. Christersson L (2015) Ekonomiska och energirelaterade resultat från avverkade och ännu växande poppel- och hybridaspbestånd $\mathrm{i}$ södra Sverige. Fakta Skog, vol 12. Sveriges lantbruksuniversitet, Uppsala

11. Larsson S, Lundmark T, Ståhl G (2009) Möjligheter till intensivodling av skog. vol Slutrapport från regeringsuppdrag. Sveriges lantbruksuniversitet

12. Eriksson H (1984) Yield of aspen and poplars in Sweden. In: Perttu $\mathrm{K}$ (ed) Ecology and management of forest biomass production systems. Dept. of Ecol. Environ. Res., Swed. Univ. Agric. Sci, Uppsala, pp 393-419

13. Schulzke R (1985) Der Internationale Populus trichocarpa Provenienz versuch von 1973/75 nach zehnjärhriger Beobachtung. Die Holzzucht 39(1-2):4-8

14. Ilstedt B (2006) Adaptation of Populus trichocarpa, giant poplar, to Swedish climate (Anpassning av Populus trichocarpa, jättepoppel, till svenskt klimat) In: Christersson L, Verwijst T (eds) Proceedings from a poplar seminar at the Department of Short Rotation Forestry, SLU, Uppsala, Sweden, 5 March 2005. Report from the Department of Crop Production Ecology(VPE), p 74

15. Ilstedt B (1996) Genetics and performance of Belgian poplar clones tested in Sweden. For Genet 3(4):183-195

16. Christersson L (2006) Biomass production of intensively grown poplars in the southernmost part of Sweden: observations of characters, traits and growth potential. Biomass Bioenergy 30(6):497508. https://doi.org/10.1016/j.biombioe.2005.10.003

17. Nielsen UB, Madsen P, Hansen JK, Nord-Larsen T, Nielsen AT (2014) Production potential of 36 poplar clones grown at medium length rotation in Denmark. Biomass Bioenergy 64:99-109. https:// doi.org/10.1016/j.biombioe.2014.03.030

18. Pliura A, Suchockas V, Sarsekova D, Gudynaite V (2014) Genotypic variation and heritability of growth and adaptive traits, and adaptation of young poplar hybrids at northern margins of natural distribution of Populus nigra in Europe. Biomass Bioenergy 70:513-529. https://doi.org/10.1016/j.biombioe.2014. 09.011

19. Ducros ET (1984) Breeding strategies with poplars in Europe. Forest Ecol Manag 8(1):23-39. https://doi.org/10.1016/03781127(84)90083-5

20. Ducros ET, Villar M, Bouvarel L, Bonduelle P (1990) Poplar improvement for short-term biomass production - the French program. Biomass Energy Industry 1 and 2:A383-A387

21. Jorge V, Dowkiw A, Faivre-Rampant P, Bastien C (2005) Genetic architecture of qualitative and quantitative Melampsora laricipopulina leaf rust resistance in hybrid poplar: genetic mapping and QTL detection. New Phytol 167(1):113-127. https://doi.org/ 10.1111/j.1469-8137.2005.01424.x

22. Clifton-Brown J, Harfouche A, Casler MD, Jones HD, Macalpine WJ, Murphy-Bokern D, Smart LB, Adler A, Ashman C, AwtyCarroll D, Bastien C, Bopper S, Botnari V, Brancourt-Hulmel M, Chen ZY, Clark LV, Cosentino S, Dalton S, Davey C, Dolstra O, Donnison I, Flavell R, Greef J, Hanley S, Hastings A, Hertzberg M, Hsu TW, Huang LS, Iurato A, Jensen E, Jin XL, Jorgensen U, Kiesel A, Kim DS, Liu J, McCalmont JP, McMahon BG, Mos M, Robson P, Sacks EJ, Sandu A, Scalici G, Schwarz K, Scordia D, Shafiei R, Shield I, Slavov G, Stanton BJ, Swaminathan K, Taylor G, Torres AF, Trindade LM, Tschaplinski T, Tuskan GA, Yamada T, Yu CY, Zalesny RS, Zong JQ, Lewandowski I (2019) Breeding progress and preparedness for mass-scale deployment of perennial lignocellulosic biomass crops switchgrass, miscanthus, willow and poplar. GCB Bioenergy 11(1):118-151. https://doi.org/10.1111/ gcbb. 12566

23. Karlsson B, Werner M, Stener LG (1996) Resultat från två klonförsök med poppel. Arbetsrapport, Uppsala

24. Stener LG (2004) Resultat från sydsvenska klontester med poppel. Arbetsrapport från Skogforsk, Uppsala

25. Stener LG (2010) Tillväxt, vitalitet och densitet för kloner av hybridasp och poppel i sydsvenska fältförsök. Arbetsrapport, Uppsala

26. Rhode A (2009) Bud set - Alandmark of the seasonal growth cycle in poplar. In: Tanino GLVWME (ed) Plant cold hardiness: from the laboratory to the field. CABI Publishing, Wallingford, pp 91-118

27. McKown AD, Klapste J, Guy RD, El-Kassaby YA, Mansfield SD (2018) Ecological genomics of variation in bud-break phenology and mechanisms of response to climate warming in Populus trichocarpa. New Phytol 220(1):300-316. https://doi.org/10.1111/ nph. 15273

28. Rohde A, Storme V, Jorge V, Gaudet M, Vitacolonna N, Fabbrini F, Ruttink T, Zaina G, Marron N, Dillen S, Steenackers M, Sabatti M, Morgante M, Boerjan W, Bastien C (2011) Bud set in poplar genetic dissection of a complex trait in natural and hybrid populations. New Phytol 189(1):106-121. https://doi.org/10.1111/j.14698137.2010.03469.x

29. Farmer RE (1993) Latitudinal variation in height and phenology of balsam poplar. Silvae Genet 42(2-3):148-153

30. Riemenschneider DE, Mcmahon BG (1993) Genetic-variation among Lake states balsam poplar populations is associated with geographic origin. For Sci 39(1):130-136

31. Savage JA, Cavender-Bares J (2013) Phenological cues drive an apparent trade-off between freezing tolerance and growth in the family Salicaceae. Ecology 94(8):1708-1717. https://doi.org/10. 1890/12-1779.1

32. Soolanayakanahally RY, Guy RD, Silim SN, Song MH (2013) Timing of photoperiodic competency causes phenological mismatch in balsam poplar (Populus balsamifera L.). Plant Cell Environ 36(1):116-127. https://doi.org/10.1111/j.1365-3040. 2012.02560.x

33. Stener LG, Westin J (2017) Early growth and phenology of hybrid aspen and poplar in clonal field tests in Scandinavia. Silva Fenn 51(3):22. https://doi.org/10.14214/sf.5656

34. Evans LM, Kaluthota S, Pearce DW, Allan GJ, Floate K, Rood SB, Whitham TG (2016) Bud phenology and growth are subject to divergent selection across a latitudinal gradient in Populus angustifolia and impact adaptation across the distributional range and associated arthropods. Ecol Evol 6(13):4565-4581. https://doi. org/10.1002/ece3.2222

35. Tharakan PJ, Robison DJ, Abrahamson LP, Nowak CA (2001) Multivariate approach for integrated evaluation of clonal biomass production potential. Biomass Bioenergy 21(4):237-247. https:// doi.org/10.1016/S0961-9534(01)00038-1

36. Abrahamson LP, White EH, Nowak CA, Briggs RD, Robison DJ (1990) Evaluating hybrid poplar clonal growth-potential in a 3year-old genetic selection field trial. Biomass 21(2):101-114. https://doi.org/10.1016/0144-4565(90)90052-L

37. Verlinden MS, Broeckx LS, Van den Bulcke J, Van Acker J, Ceulemans R (2013) Comparative study of biomass determinants of 12 poplar (Populus) genotypes in a high-density short-rotation culture. Forest Ecol Manag 307:101-111. https://doi.org/10.1016/j. foreco.2013.06.062

38. Isik F, Toplu F (2004) Variation in juvenile traits of natural black poplar (Populus nigra L.) clones in Turkey. New Forest 27(2):175-187. https://doi.org/10.1023/A:1025071515826

39. Niemczyk M, Przybysz P, Przybysz K, Karwanski M, Kaliszewski A, Wojda T, Liesebach M (2019) Productivity, growth patterns, and cellulosic pulp properties of hybrid Aspen clones. Forests 10(5): ARTN 450. https://doi.org/10.3390/f10050450 
40. Brodie LC, Debell DS (2004) Evaluation of field performance of poplar clones using selected competition indices. New Forest 27(3): 201-214

41. Becker WA (1992) Manual of quantitative genetics, 5th edn. Academic Enterprises, Pullman

42. Stener LG, Karlsson B (2004) Improvement of Populus tremula $x$ P. tremuloides by phenotypic selection and clonal testing. For Genet 11(1):13-27

43. White TL, Adams WT, Neale DB (2007) Forest genetics. CABI Pub, Wallingford

44. Falconer DS (1996) Introduction to quantitative genetics, 4th edn. Longman, Harlow

45. Namkoong G, Conkle MT (1976) Time trends in genetic-control of height growth in ponderosa pine. For Sci 22(1):2-12

46. Hodge GR, White TL (1992) Genetic parameter estimates for growth traits at different ages in slash pine and some implications for breeding. Silvae Genet 41(4-5):252-262

47. Osorio LF, White TL, Huber DA (2001) Age trends of heritabilities and genotype-by-environment interactions for growth traits and wood density from clonal trials of Eucalyptus grandis Hill ex Maiden. Silvae Genet 50(1):30-37

48. Osorio LF, White TL, Huber DA (2003) Age-age and trait-trait correlations for Eucalyptus grandis Hill ex Maiden and their implications for optimal selection age and design of clonal trials. Theor Appl Genet 106(4):735-743

49. Kroon J, Andersson B, Mullin TJ (2008) Genetic variation in the diameter-height relationship in Scots pine (Pinus sylvestris). Can $\mathrm{J}$ For Res 38(6):1493-1503. https://doi.org/10.1139/X07-233

50. Apuli R-P, Richards T, Rendon M, Karacic A, Wästljung A-CR, Ingvarsson PK (2020) The genetic basis of adaptation in phenology in an introduced population of Black Cottonwood (<em $>$ Populus trichocarpa</em $>$, Torr. \&amp; Gray). bioRxiv: 2020.2006.2017.156281. doi:https://doi.org/10.1101/2020.06.17. 156281

51. Lutter R, Tullus A, Tullus T, Tullus H (2016) Spring and autumn phenology of hybrid aspen (Populus tremula L. x P. tremuloides Michx.) genotypes of different geographic origin in hemiboreal Estonia. Nz J Forest Sci 46:ARTN 20. https://doi.org/10.1186/ s40490-016-0078-7

52. Maurya JP, Bhalerao RP (2017) Photoperiod- and temperaturemediated control of growth cessation and dormancy in trees: a molecular perspective. Ann Bot-London 120(3):351-360. https:// doi.org/10.1093/aob/mcx061

53. Singh RK, Svystun T, AlDahmash B, Jonsson AM, Bhalerao RP (2017) Photoperiod- and temperature-mediated control of phenology in trees - a molecular perspective. New Phytol 213(2):511-524. https://doi.org/10.1111/nph.14346

54. Michelson IH, Ingvarsson PK, Robinson KM, Edlund E, Eriksson ME, Nilsson O, Jansson S (2018) Autumn senescence in aspen is not triggered by day length. Physiol Plant 162(1):123-134. https:// doi.org/10.1111/ppl.12593
55. Schreiber SG, Ding C, Hamann A, Hacke UG, Thomas BR, Brouard JS (2013) Frost hardiness vs. growth performance in trembling aspen: an experimental test of assisted migration. J Appl Ecol 50(4):939-949. https://doi.org/10.1111/1365-2664.12102

56. Yu QB, Tigerstedt PMA, Haapanen M (2001) Growth and phenology of hybrid aspen clones (Populus tremula L. x Populus tremuloides Michx.). Silva Fenn 35(1):15-25. https://doi.org/10. 14214/sf.600

57. Elferjani R, DesRochers A, Tremblay F (2016) Plasticity of bud phenology and photosynthetic capacity in hybrid poplar plantations along a latitudinal gradient in northeastern Canada. Environ Exp Bot 125:67-76. https://doi.org/10.1016/j.envexpbot.2016.01.007

58. Richardson AD, Black TA, Ciais P, Delbart N, Friedl MA, Gobron N, Hollinger DY, Kutsch WL, Longdoz B, Luyssaert S, Migliavacca M, Montagnani L, Munger JW, Moors E, Piao SL, Rebmann C, Reichstein M, Saigusa N, Tomelleri E, Vargas R, Varlagin A (2010) Influence of spring and autumn phenological transitions on forest ecosystem productivity. Philos T R Soc B 365(1555):3227-3246

59. McKown AD, Guy RD, Klapste J, Geraldes A, Friedmann M, Cronk QCB, El-Kassaby YA, Mansfield SD, Douglas CJ (2014) Geographical and environmental gradients shape phenotypic trait variation and genetic structure in Populus trichocarpa. New Phytol 201(4):1263-1276. https://doi.org/10.1111/nph.12601

60. Wang L, Tiffin P, Olson MS (2014) Timing for success: expression phenotype and local adaptation related to latitude in the boreal forest tree, Populus balsamifera. Tree Genet Genomes 10(4):911922. https://doi.org/10.1007/s11295-014-0731-3

61. Way DA, Montgomery RA (2015) Photoperiod constraints on tree phenology, performance and migration in a warming world. Plant Cell Environ 38(9):1725-1736. https://doi.org/10.1111/pce.12431

62. Stener LG, Westin $J$ (2018) Resultat efter sju års tillväxt i tio fältförsök med hybridasp och poppel: slutrapport 2017 för Energimyndighetens projekt 41902-1RT 2017 Arbetsrapport. Swedish Forestry Institute - Skogforsk, Uppsala

63. Niemczyk M, Wojda T, Kaliszewski A (2016) Biomass productivity of selected poplar (Populus spp.) cultivars in short rotations in northern Poland. Nz J Forest Sci 46:ARTN 22. https://doi.org/10. 1186/s40490-016-0077-8

64. Niemczyk M, Wojda T, Kantorowicz W (2016) Silvicultural potential of selected poplar cultivars growing on short rotation plantations. Sylwan 160(4):292-298

65. Benetka V, Novotna K, Stochlova P (2014) Biomass production of Populus nigra L. clones grown in short rotation coppice systems in three different environments over four rotations. Iforest 7:233-239. https://doi.org/10.3832/ifor1162-007

Publisher's Note Springer Nature remains neutral with regard to jurisdictional claims in published maps and institutional affiliations. 